NBER WORKING PAPER SERIES

\title{
A THEORY OF INCOME SMOOTHING WHEN INSIDERS KNOW MORE THAN OUTSIDERS
}

\author{
Viral V. Acharya \\ Bart M. Lambrecht \\ Working Paper 17696 \\ http://www.nber.org/papers/w17696
}

\author{
NATIONAL BUREAU OF ECONOMIC RESEARCH \\ 1050 Massachusetts Avenue \\ Cambridge, MA 02138
}

December 2011

We are grateful to Phil Brown, Peter Easton, Stew Myers, John O'Hanlon, Ken Peasnell, Joshua Ronen, Stephen Ryan, Lakshmanan Shivakumar and Steve Young for insightful discussions. Comments can be sent to Viral Acharya (vacharya @stern.nyu.edu) or Bart Lambrecht (b.lambrecht@lancaster.ac.uk). The views expressed herein are those of the authors and do not necessarily reflect the views of the National Bureau of Economic Research.

NBER working papers are circulated for discussion and comment purposes. They have not been peerreviewed or been subject to the review by the NBER Board of Directors that accompanies official NBER publications.

(C) 2011 by Viral V. Acharya and Bart M. Lambrecht. All rights reserved. Short sections of text, not to exceed two paragraphs, may be quoted without explicit permission provided that full credit, including (C) notice, is given to the source. 
A Theory of Income Smoothing When Insiders Know More Than Outsiders

Viral V. Acharya and Bart M. Lambrecht

NBER Working Paper No. 17696

December 2011

JEL No. D82,D92,G32,G35,M41,M42,O43

\begin{abstract}
$\underline{\text { ABSTRACT }}$
We consider a setting in which insiders have information about income that outside shareholders do not, but property rights ensure that outside shareholders can enforce a fair payout. To avoid intervention, insiders report income consistent with outsiders' expectations based on publicly available information rather than true income, resulting in an observed income and payout process that adjust partially and over time towards a target. Insiders under-invest in production and effort so as not to unduly raise outsiders' expectations about future income, a problem that is more severe the smaller is the inside ownership and results in an "outside equity Laffer curve". A disclosure environment with adequate quality of independent auditing mitigates the problem, implying that accounting quality can enhance investments, size of public stock markets and economic growth.
\end{abstract}

Viral V. Acharya

Stern School of Business

New York University

44 West 4th Street, Suite 9-84

New York, NY 10012

and NBER

vacharya@stern.nyu.edu

Bart M. Lambrecht

Lancaster University Management School

Room C-42

Bailrigg

Lancaster LA1 4YX, UK

b.lambrecht@lancaster.ac.uk 


\section{Introduction}

A fundamental property right conferred upon stockholders of a firm is that they are entitled to their fair share of the firm's (distributable) net income. Since stock ownership is verifiable, this right is relatively easy to enforce provided that everyone agrees on what the income is. In a world of complete information, determining net income should be a relatively simple matter because it is clear to everyone to see how much money is left on the table after all senior claimants (creditors, managers, employees, taxman, ...) have been paid. Matters become more tricky in a world of asymmetric information where inside shareholders may know more than outside shareholders.

How is income reported and payout determined if asymmetric information is a fact of life? What are the effects of information asymmetry on insiders' production decision or incentives to put in effort? How does asymmetric information affect the time-series properties of reported income and payout? How does inside ownership affect income and operating efficiency? These are some of the questions we try to address in this paper.

We consider an all-equity financed firm that pays out each period all realized income. In our model outsiders can extract their share of income from the firm by a threat of collective action against insiders 1 While under symmetric information outsiders know exactly what they are due, under asymmetric information outsiders refrain from intervention for as long as the reported income (and corresponding payout) meets their expectations. Outsiders (supported by analysts) form their expectations about income on the basis of the information available to them. Outsiders' income estimate is unbiased and "best" based on the information they have available, and it is therefore rational for them to require a payout that is consistent with their expectations. ${ }^{2}$ Hence,

\footnotetext{
${ }^{1}$ If collective action is costly (as in Myers (2000), Jin and Myers (2006), Lambrecht and Myers (2007, 2008), Acharya, Myers and Rajan (2011), among others) then this gives insiders scope to extract rents, which erodes outsiders' stake in the firm's income and the value of the outside equity. A strictly positive cost of intervention is not central to our paper. We rule out, however, the possibility that property rights are void and outsiders cannot extract any income from the firm as this would completely undermine the firm's capability to raise outside equity in the first place.

${ }^{2}$ Policies where insiders pay out according to realized income would be "fragile" for insiders. For instance, if realized payouts are repeatedly below outsiders' estimates, then outsiders may believe they are being taken for a ride by insiders and intervene.
} 
when the strength of property rights and pressure by outside investors keeps insiders to the straight and narrow, the equilibrium payout will be smooth compared to realized income as it is based on outsiders' expectation. Insiders absorb short-term variation in income and, if necessary, have to "find the money" to keep outside investors at bay.

So far smoothing is fairly harmless in that it merely irons out variation in reported income. We call it "financial smoothing" because it merely alters the time pattern of reported income (through borrowing and savings) without changing the firm's underlying cash-flows as determined by insiders' production and effort decisions. Insiders may, however, also engage in "real smoothing" by manipulating production and effort decisions in an attempt to "manage" outsiders' expectations. In particular, suppose outsiders cannot observe value-relevant variables (such as marginal costs) directly but have to rely on an incomplete set of observable proxies (such as output or sales) in order to infer income indirectly. Then insiders may have an incentive to distort the observable proxy variables in order to lower outsiders' expectations about current and future income. The logic of this results is as follows.

Suppose that outsiders can observe realized sales (revenues) but not costs. In particular, the firm's marginal cost is a stochastic latent variable. While outsiders do not know the realization of the marginal cost, the parameters that drive the marginal cost process are common knowledge. As before outsiders expect their fair share of income. Insiders know that outsiders associate a higher sales level with lower marginal costs. Therefore, upon observing higher sales, outsiders expect income to be higher and want higher payout. In an attempt to manage outsiders' expectations, insiders underproduce and cut output up to the point where the cost in terms of reducing expected income equals the benefit of lowering outsiders' payout expectations.

In contrast, in an environment of symmetric information where payout to outsiders is a function of actual income (i.e., cash-flows), insiders determine the firm's output (and sales) level at the first-best by setting marginal costs equal to marginal revenues ${ }^{3}$

Now, though insiders underproduce in order to manage outsiders' expectations, in equilibrium they are not successful in their attempt because insiders anticipate what is going on and can still infer from sales the value of the latent cost variable if that is the

\footnotetext{
${ }^{3}$ In effect, insiders have an incentive to maximize total firm value and to put in the optimal effort level if they get (i) a constant fraction of the firm's actual (i.e., realized) income and, (ii) a perfectly competitive remuneration (taken upfront out of gross revenues) for their cost of effort.
} 
only unobservable (i.e., assuming there are no other unknowns to outsiders). Reported income therefore coincides with actual income. Nevertheless, indirect inference of costs through sales distorts insiders' actions and traps them into behaving sub-optimally.

Next, assume that observed sales are affected each period by an additive, independently and identically distributed, noise term, the realization of which is unknown to insiders at the time when they set the output level. The noise term could, for instance, reflect measurement error. Such noise causes sales to become an imperfect (noisy) measure of the latent marginal cost variable. As a result outsiders can no longer infer the exact realization of actual income because they do not know whether a change in sales is due to measurement error or a change in the latent cost variable. However, since measurement errors are transitory and shocks to costs persistent, the underlying source of change gradually becomes clear over time. Therefore, outsiders calculate their best estimate of income on the basis of not only current sales but also past sales. Indeed, while the current sales figure could be unduly influenced by measurement error, an estimate based on the full sales history smooths out the effect of these errors.

Formally, outsiders' income estimate is the solution to a filtering problem. We adopt in particular the Kalman filter because for our linear model with Gaussian disturbances the Kalman filter gives an unbiased, minimum variance and consistent estimate of actual (i.e., realized) income 4 While at any given time the Kalman filter is an inexact estimate of actual income, the measure is right on average and optimal among all possible estimators.

Then, in a rational expectations equilibrium outsiders calculate their expectation of actual income on the basis of realized sales and of what they believe insiders' optimal output and effort policy to be. Conversely, insiders determine each period their optimal effort and output policy given outsiders' beliefs. In equilibrium insiders' actions are consistent with outsiders' beliefs and outsiders' expectations are unbiased conditional on the information available. Each period outsiders receive a payout that equals their share of what they expect income to be. Insiders also get a payout but they have to soak up any under (over) payment to outsiders as some kind of discretionary remuneration (charge): if actual income is higher (lower) than outsiders' estimate then insiders cash in (make up for) the difference in outsiders' payout.

\footnotetext{
${ }^{4}$ For an early forecasting application of the Kalman filter in the context of earnings numbers, see Lieber, Melnick, and Ronen (1983), who use the filter to deal with transitory noise in earnings.
} 
We thus obtain "income smoothing" because insiders report an income figure that corresponds to outsiders' beliefs. Consequently, reported income and payout are smooth compared to actual income not because insiders want to smooth income, but because insiders have to meet outsiders' expectations to avoid intervention. Importantly, smoothing also happens in an inter-temporal sense. The efficient output and effort level is determined in our model by the contemporaneous level only of the latent marginal cost variable; however, the current effort and output decision not only affect current sales levels but also outsiders' expectations of current and all future income. This exacerbates the previously discussed negative externality for insiders because bumping up sales now means the outsiders will expect higher income and payout not only now but also in future. Even though the spillover effect of a one-off increase in sales on outsiders' future expectations wears off over time, it still causes insiders to underproduce even more and to put in even lower effort compared to what is first best. 5

There is direct support for our model in the survey-based findings of Graham, Harvey, and Rajgopal (2005): (i) insiders (managers) always try to meet outsiders' earnings per share (EPS) expectations at all costs to avoid serious repercussions; and, (ii) many managers under-invest to smooth earnings and therefore engage in real smoothing. The first is one of the key premises of our model and the second is a key implication of the model ${ }^{6}$ There is also indirect support for our model from the accounting literature. For example, Roychowdhury (2006) finds evidence consistent with managers manipu-

${ }^{5}$ We stress that intertemporal smoothing in our model does not result from risk aversion because all agents are risk neutral. If insiders' utility were a concave function of reported income then this alone could be sufficient to generate smoothing in reported income. Managerial or insider risk aversion is a pervasive feature and key driver in existing papers on income smoothing (see related literature in section 5). Graham (2003) also explains and describes existing evidence that convexity of corporate taxes in firm profits can lead to income smoothing, though it is unclear it should lead to "real" smoothing.

${ }^{6}$ In our model insiders maximize the present value of their income stream subject to meeting outsiders' income expectation. Insiders' actions are driven by "profit satisficing" (see Simon (1955)) and not by an "optimal" contract. Simon contrasts satisficing with optimization theory. The contrast is between "looking for the sharpest needle in the haystack" (optimizing) and "looking for a needle sharp enough to sew with" (satisficing) (Simon (1987), p244). The latter may be preferable once agents' bounded rationality and the complexity of the decision environment are taken into account. Recently the idea of satisficing has also been extended to contracting problems: Bolton and FaureGrimaud (2010) formalize the notion that boundedly rational agents write satisficing contracts rather 
lating real activities to avoid reporting annual losses. There is also some evidence of real activities manipulation to meet annual analyst forecasts.

Our theory of intertemporal income smoothing yields rich, testable and novel implications on the time-series properties of reported income and payout to outsiders. First, "reported income" is smooth compared to "actual income" because the former is based on outsiders' expectations whereas the latter corresponds to actual cash flow realizations. Second, reported income follows inter-temporally a target adjustment model. The "income target" is a linear, increasing function of sales, so that when there is a shock to sales (and therefore to the income target), reported income adjusts towards the new target, but adjustment is partial and distributed over time because outsiders only gradually learn whether a shock to sales is due to measurement error or due to a fundamental shift in the firm's cost structure. Third, the current level of reported income can be expressed as a distributed lag model of current and past sales, where the weights on sales decline as we move further in the past. Since payout to outsiders is a fraction of reported income, it follows that also payout can be expressed as a distributed lag model of sales. Equivalently, current payout can be expressed as a target adjustment model where current payout depends on current sales and previous period's payout, which is similar to the Lintner (1956) dividend model ${ }^{7}$ Fourth, the total amount of smoothing can be broken up in two components: "real" smoothing and "financial" smoothing. While the latter does not alter the underlying cash flows, the former results in under-investment and implies that the output level (and therefore sales) becomes less sensitive to variation in the latent cost variable $\mathrm{P}^{8}$

than optimal contracts.

${ }^{7} \mathrm{~A}$ difference is that in the Lintner model target payout is linked to contemporaneous net income and not contemporaneous sales. This difference follows from the fact that sales (and not income) is the observable "anchor" variable in our model.

${ }^{8} \mathrm{We}$ do not model how real and financial smoothing are actually implemented. The interested reader is referred to the book by Ronen and Sadan (1981) in which various smoothing mechanisms are discussed and illustrated in great detail. For an illustrative case example, we refer to the highly publicized settlement that Microsoft reached with the SEC in 2002. The settlement marked the end to years of investigation by the SEC over allegations that Microsoft was employing "cookie jar" accounting practices in which it put aside income in certain quarters to pad future financial results when the company did not meet expectations. The SEC said that Microsoft maintained seven reserve accounts that did not comply with GAAP, because they did not have "adequately substantial bases." Still, under the settlement agreement Microsoft is admitting no explicit wrongdoing and is not obliged 
Importantly, smoothing increases with the degree of information asymmetry between insiders and investors. Holding constant the degree of information asymmetry (as determined by the variance of the measurement error), smoothing and underproduction in particular also increase with the outside shareholders' ownership stake. Conversely, a higher level of inside ownership leads to less real smoothing. Indeed, the under-investment problem disappears as insiders move towards $100 \%$ ownership $9^{9}$ We show that these effects lead to an "outside equity Laffer curve": the value of the total outside equity is an inverted U-shaped function of outsiders' ownership stake. The analogy with the taxation literature is straightforward: outsiders' ownership stake acts ex post like a proportional tax on distributable income and undermines insiders' incentives to produce and put in effort.

This final result suggests that low inside ownership could have detrimental consequences for the firm. We argue then that since outside equity may be crucial for the development and expansion of owner-managed firms, our results offer a rationale for imposing disclosure requirements on public companies and for improving accounting and auditing quality. We show that, all else equal, introducing independent accounting information, such as an unbiased but imprecise income estimate, improves economic efficiency, increases the outside equity value, and acts as a substitute for a higher inside ownership stake. The implication is that accounting quality, investments, size of public stock markets, and economic growth are all positively correlated in our model, and as empirically found in empirical literature on finance and growth (King and Levine (1993), Rajan and Zingales (1998) among others).

The rest of the paper is organized as follows. Section 1 presents the benchmark case with symmetric information between outsiders and insiders. Section 2 analyzes the asymmetric information model. Section 3 discusses the robustness and extensions of the model, in particular, the insiders' participation constraint and the value of audited disclosure. Section 4 presents additional empirical implications. Section 5 to pay a fine.

${ }^{9}$ Intuitively, the smaller the insiders' stake, the smaller is the group of insiders that has to soak up income shocks for a larger group of outsiders. Any variation in sales feeds into outsiders' expectations and is "levered" up to the extent that insiders own a smaller stake. This creates an incentive for insiders to underproduce and to make output (and therefore sales) less sensitive to changes in the latent cost variable. In the extreme case where insiders have no stake left in the firm they produce little or nothing, irrespective of the marginal cost level. 
briefly relates our paper to existing literature. Section 6 concludes. Proofs are in the appendix.

\section{Symmetric information case}

Consider a firm with access to a productive technology. The output from the technology is sold at a fixed unit price, but its scale can be varied. Marginal costs of production follow an $\mathrm{AR}(1)$ process with a drift that depends on the effort exercised by the technology operators. Each period marginal costs are revealed before the output scale is chosen. A part of the firm is owned by risk-neutral shareholders (outsiders) and the rest by risk-neutral insiders who also act as the technology operators. To start with, we focus on the first-best scenario in which there is congruence of objectives between outsiders and insiders, and information about marginal costs is known symmetrically to both outsiders and insiders.

Formally, we consider a firm with the following income function:

$$
\begin{gathered}
\pi_{t}=q_{t}-\frac{q_{t}^{2}}{2 x_{t}}-\frac{1}{2} c e_{t}^{2} \\
\text { where } x_{t}=A x_{t-1}+B e_{t}+w_{t-1} \text { with } w_{t-1} \sim N(0, Q),
\end{gathered}
$$

$e_{t}$ and $q_{t}$ denote the chosen effort and output level. The (inverse) marginal production cost variable $x_{t}$ follows an $\mathrm{AR}(1)$ process with auto-regressive coefficient $A \in[0,1)$ (so that the effect of current effort on future values of $x$ declines over time), a drift $B e_{t}$, and an i.i.d. noise term $w_{t-1}$. The term $c e_{t}^{2} / 2$ represents the cost of effort expressed in monetary terms. Effort increases the value for $x_{t}$, which in turn lowers the firm's marginal cost of production. Effort therefore increases the efficiency of the firm's production process. $e_{t}$ and $q_{t}$ are implemented after the realization of $w_{t-1}$ is observed.

All shareholders are risk-neutral, can borrow and save at the risk free rate, and have a discount factor $\beta \in(0,1)$. The value of the firm is given by the present value of discounted income:

$V_{t}=\max _{e_{t+j}, q_{t+j}, j=0 \ldots \infty} E_{t}\left[\sum_{j=0}^{\infty} \beta^{j} \pi_{t+j}\right]=\max _{q_{t+j}, j=0 \ldots \infty} E_{t}\left[\sum_{j=0}^{\infty} \beta^{j}\left(q_{t+j}-\frac{q_{t+j}^{2}}{2 x_{t+j}}-\frac{1}{2} c e_{t+j}^{2}\right)\right]$

Then, the first-best policies that maximize firm value are as follows. 
Proposition 1 The first-best production policy and effort level are respectively

$$
\begin{aligned}
q_{t}^{o} & =x_{t}, \\
e_{t}^{o} & =\frac{B}{2 c(1-\beta A)} \equiv e^{o} .
\end{aligned}
$$

The firm's actual (i.e., realized) income and total payout under the first-best policy are given by:

$$
\pi_{t}^{o}=\frac{x_{t}}{2}-\frac{1}{2} c e^{o 2}
$$

The proposition shows that the first-best effort is constant over time and increasing in the autoregressive coefficient $A$, because with non-zero autocorrelation $(A>0)$ the effort level $e_{t}$ not only affects the contemporaneous level of $x_{t}$, but also all future levels $x_{t+i}$.

The first-best output level $q_{t}^{o}$ equals $x_{t}$. Recall that a higher value for $x_{t}$ implies lower marginal costs. Therefore, the output level rises with $x_{t}$. As $x_{t}$ goes to zero, marginal costs spiral out of control and the first-best output quantity goes to zero. Since the shocks that drive $x_{t}$ are normally distributed, marginal costs could theoretically become negative. The solution in proposition 1 no longer makes sense for negative $x_{t}$ because marginal costs can, of course, not be negative. The likelihood of negative values for $x_{t}$ arising is, however, negligible small if the stationary unconditional mean of $x_{t}$ (given by $\frac{B e}{1-A}$ ) is sufficiently large relative to the unconditional variance of $x_{t}$ (given by $\frac{Q}{1-A^{2}}$ ). We assume this condition to be satisfied so that we can safely ignore the occurrence of negative costs 10

Finally, note that there is a mapping from the cost variable $\left(x_{t}\right)$ to the output level $\left(q_{t}\right)$ and the actual income level $\left(\pi_{t}\right)$. This is important for section 2 where $x_{t}$ is unobservable to outside shareholders and has to be inferred from an observable proxy.

\footnotetext{
${ }^{10}$ To rule out negative values for $x_{t}$ altogether one could assume that $x_{t}$ is log-normally distributed. This would, however, make the Bayesian updating process deployed in next section completely intractable. We will therefore stick to the normal distribution throughout this paper. The normality assumption is standard in the information economics literature. For example, Kyle (1985) and the large number of papers that originated from this paper all assume for sake of tractability that asset prices are normally distributed.
} 


\subsection{Inside and outside shareholders}

So far we have assumed that all shareholders can be treated as a homogenous group that controls the firm. We now relax this assumption by introducing inside and outside shareholders who, respectively, own a fraction $(1-\varphi)$ and $\varphi$ of the shares, $\varphi \in[0,1]$. For example, insiders (managers and even board members involved in firm's operating decisions) typically own the majority of shares of private firms $(\varphi<0.5)$, whereas for public firms it is more common that outsiders own the majority of shares $(\varphi>0.5)$.

Insiders set production policy $\left(q_{t}\right)$ and exert effort $\left(e_{t}\right)$. We assume that the market for insiders is competitive with their reservation wages normalized to zero, so that insiders get a monetary compensation that equals their total cost of effort (i.e., $\left.c e_{t}^{2} / 2\right)$. Under symmetric information outsiders can infer from $x_{t}$ (or $q_{t}$ ) exactly how much effort insiders exert. Outsiders can therefore pay the competitive remuneration for the exerted effort. In our model partial ownership does not by itself distort insiders' effort because the efficient outcome is achieved under symmetric information. Paying a competitive wage for effort exerted allows us to abstract from compensation issues and to focus purely on the conflict between inside and outside shareholders that results from asymmetric information ${ }^{11}$

Analogous to Fluck (1998), Myers (2000), Jin and Myers (2006), Lambrecht and Myers (2007, 2008, 2011), and Acharya, Myers and Rajan (2011), we assume that insiders operate subject to a threat of collective action. Outsiders' payoff from collective action is given by $\varphi \alpha V_{t}$ where $\alpha(\in[0,1])$ reflects the degree of investor protection.

To avoid collective action, insiders pay out each period a dividend $d_{t}$ that leaves outsiders indifferent between intervening and leaving insiders unchallenged for another period. If $S_{t}$ denotes the value of the outside equity then $d_{t}$ is defined by ${ }^{12}$

$$
\begin{aligned}
S_{t}=d_{t}+\beta \alpha \varphi E_{t}\left[V_{t+1}\right] & =\alpha \varphi V_{t} \\
\Longleftrightarrow d_{t}+\beta \alpha \varphi E_{t}\left[V_{t+1}\right] & =\alpha \varphi \pi_{t}+\alpha \varphi \beta E_{t}\left[V_{t+1}\right] \Longleftrightarrow d_{t}=\alpha \varphi \pi_{t}
\end{aligned}
$$

\footnotetext{
${ }^{11}$ Graham, Harvey, and Rajgopal (2005) report that CFOs view compensation motivation as a second-order factor, at best, for smoothing earnings.

${ }^{12}$ It is not strictly necessary that all income is paid out each period. For example, if reported income earns the risk-free rate of return within the firm (e.g. through a high yield cash account) and is protected from expropriation by insiders, then outsiders do not require income to be paid out (see Lambrecht and Myers (2011) for a model where the firm borrows and saves at the safe rate).
} 
Equation (7) can be interpreted as a capital market constraint that requires insiders to provide an adequate return to outside investors. Graham et al. (2005) provide convincing evidence of the importance of capital market pressures and how they induce managers to meet earnings targets at all costs ${ }^{13}$

$\varphi$ denotes outsiders' "nominal" ownership stake. Scaling the nominal ownership stake by the degree of investor protection $\alpha$ gives outsiders' "real" ownership state $\theta \equiv \varphi \alpha$. It follows that the payouts to outsiders $\left(d_{t}\right)$ and insiders $\left(r_{t}\right)$ are respectively given by $\theta \pi_{t}$ and $(1-\theta) \pi_{t}$. Income $\left(\pi_{t}\right)$ is calculated net of insiders' compensation for effort exerted, and is shared between insiders and outsiders according to their real ownership stake ${ }^{14}$ The following corollary results at once.

Corollary 1 If insiders are paid a competitive wage for their efforts and all shareholders have symmetric information then insiders adopt the first-best production and effort levels, and payout to outsiders (insiders) equals a fraction $\theta(1-\theta)$ of realized income $\pi_{t}$.

\section{Asymmetric information}

We now add two new ingredients to the model. First, we introduce asymmetric information regarding the actual realizations of the stochastic variable $x_{t}$ by assuming that these are only observed by insiders. All model parameters remain common knowledge, however. Outsiders also have an unbiased estimate $\hat{x}_{0}$ of the initial value $x_{0}{ }^{15}$

Second, outsiders observe the output level $q_{t}$ with some measurement error. Instead of observing $q_{t}$, insiders observe $s_{t} \equiv q_{t}+\epsilon_{t}$ where $\epsilon_{t}$ is an i.i.d. normally distributed noise term with zero mean and variance $R$ (i.e., $\epsilon_{t} \sim N(0, R)$ ). The measurement

\footnotetext{
${ }^{13}$ As one surveyed manager put it: "I miss the target, I'm out of a job." The perception of outside investors is such that if insiders cannot "find the money" to hit the earnings target then the firm is in serious trouble.

${ }^{14}$ The amount of effort exerted can be inferred from $x_{t}$ or $q_{t}$.

${ }^{15} \hat{x}_{0}$ is revealed to outside investors when the firm is set up at time zero. See section 3.3 for further details.
} 
error is uncorrelated with the marginal cost variable $x_{t}$ (i.e., $E\left(w_{k} \epsilon_{l}\right)=0$ for all $k$ and $l$ ). In what follows we refer to $s_{t}$ as the firm's "sales" as perceived by outsiders, i.e., outsiders perceive the firm's revenues to be $s_{t}$, whereas in reality they are $q_{t}{ }^{16}$ Outsiders are aware that sales are an imperfect proxy for economic output and they know the distribution from which $\epsilon_{t}$ is drawn. Importantly, insiders implement effort $\left(e_{t}\right)$ and output $\left(q_{t}\right)$ after the realization of $x_{t}$ but before the realization of $\epsilon_{t}$ is known. Since $\epsilon_{t}$ is value-irrelevant noise, the firm's actual income is still given by $\pi_{t}=q_{t}-$ $\frac{q_{t}^{2}}{2 x_{t}}-\frac{1}{2} c e_{t}^{2}$. However, as $q_{t}, x_{t}$ and $e_{t}$ are unobservable outsiders have to estimate income on the basis of noisy sales figures. Therefore measurement errors can lead to misvaluation in the firm's stock price.

We know from previous section that there is a mapping from the latent variable $x_{t}$ to both $q_{t}$ and $\pi_{t}$. The presence of the noise term $\epsilon_{t}$ obscures, however, this link and makes it impossible for outsiders exactly to infer $x_{t}$ and $\pi_{t}$ from sales. (Recall that insiders know $x_{t}$ but not $\epsilon_{t}$ when setting output $q_{t}$ and effort $e_{t}$.)

Assuming that insiders cannot trade in the firm's stock and that the information asymmetry cannot be mitigated through monitoring or some other mechanism (we return to this in section 3.2 , , the best outsiders can do is to calculate a probability distribution of income, $\pi_{t}$, on the basis of all information available to them. This information set $I_{t}$ is given by the full history of current and past sales prices, i.e., $I_{t} \equiv\left\{s_{t}, s_{t-1}, s_{t-2} \ldots\right\}$. In particular, we show that on the basis of the initial estimate $\hat{x}_{0}$ and the sales history, $I_{t}$, outsiders can infer a probability distribution for the latent marginal cost variable $x_{t}$, which in turn maps into a probability distribution for income $\pi_{t}$.

Formally, the outsiders obtain an estimator $\hat{x}_{t}$ for $x_{t}$ using a Kalman filter. The estimator $\hat{x}_{t}$ depends in general not only on the latest sales figure $s_{t}$ but on the entire available history $I_{t}$ of sales. However, since past sales figures become "stale" with time and therefore less reliable to infer the current level of $x_{t}$, the Kalman filter resolves the problem by calculating a weighted average of sales where more recent sales carry a higher weight. The Kalman estimate $\hat{x}_{t}$ is unbiased (see Chui and Chen (1991) page 40): $\hat{x}_{t}=E\left[x_{t} \mid I_{t}\right] \equiv E_{S, t}\left[x_{t}\right]$ for all $t$, where the subscript $S$ in $E_{S, t}\left[x_{t}\right]$ emphasizes

\footnotetext{
${ }^{16}$ For further details on the sources and properties of measurement errors we refer to the extensive literature on income measurement in economics, accounting and statistics (see Beaver (1979), Demski and Sappington (1990) and Moore, Stinson, and Welniak (2000), among others).
} 
(outside) shareholders' expectation at time $t$ of $x_{t}$ based on the information set $I_{t}$. The Kalman filter is also optimal ("best") in the sense that it minimizes the mean square error (see Gelb (1974)). ${ }^{17}$ We focus on the steady state or "limiting" Kalman filter which results if the history of sales $I_{t}$ is sufficiently long 18 The steady-state Kalman filter allows us to analyze the long-run behavior of reported income and payout.

One might think that the amount of information to keep track of becomes unmanageable as the sales history becomes longer. Fortunately, this is not the case because the Kalman filter works recursively and only requires previous period's best estimate $\hat{x}_{t-1}$ and current sales $s_{t}$ to calculate a new estimate $\hat{x}_{t}$. The past history of sales is therefore encapsulated in previous period's estimate of the latent variable. The new best estimate $\hat{x}_{t}$ is a weighted average of $\hat{x}_{t-1}$ and $s_{t}$. The most weight is given to the number that carries the least uncertainty (similar to Bayesian updating). $\hat{x}_{t-1}$ is, in turn, a weighted average of $s_{t-1}$ and $\hat{x}_{t-2}$. This recursive algorithm works all the way back to the initial time $t=0$, at which point we need the initial estimate $\hat{x}_{0}$ for $x_{0}$ to start the algorithm.

We can show that with asymmetric information actual income is still linear in $x_{t}$ under the insiders' optimal production policy. Hence, using their best, unbiased estimate $\hat{x}_{t}$, outsiders can calculate the best, unbiased estimate $\hat{\pi}_{t}$ of the firm's income (i.e., $\left.\hat{\pi}_{t}=E_{S, t}\left[\pi_{t}\right]\right)$. It is rational for outside shareholders to demand a payout $d_{t}$ that equals $d_{t}=\theta E_{S, t}\left(\pi_{t}\right)$ where $E_{S, t}\left(\pi_{t}\right) \equiv E\left[\pi_{t} \mid s_{t}, s_{t-1}, s_{t-2}, \ldots\right]$. Indeed, the capital market constraint requires that $d_{t}$ satisfies the following constraint:

$$
\begin{aligned}
S_{t}=d_{t}+\beta \varphi \alpha E_{S, t}\left[V_{t+1}\right] & =\varphi \alpha E_{S, t}\left[V_{t}\right] \\
\Longleftrightarrow d_{t}+\beta \varphi \alpha E_{S, t}\left[V_{t+1}\right] & =\varphi \alpha E_{S, t}\left[\pi_{t}\right]+\varphi \alpha \beta E_{S, t}\left[V_{t+1}\right] \Longleftrightarrow d_{t}=\theta E_{S, t}\left[\pi_{t}\right]
\end{aligned}
$$

In other words, outsiders want their share of the income they believe has been realized according to all information available to them.

While insiders cannot manage outsiders' expectations through words (which are not credible) they can do so through their actions. Managers can influence observable sales

\footnotetext{
${ }^{17}$ If the disturbances $\left(\epsilon_{t}\right.$ and $\left.w_{t}\right)$ and the initial state $\left(x_{0}\right)$ are normally distributed then the Kalman filter is unbiased. When the normality assumption is dropped unbiasedness may no longer hold, but the Kalman filter still minimizes the mean square error within the class of all linear estimators.

${ }^{18}$ Under mild conditions (see appendix) the Kalman filter converges to its steady state. Convergence is of geometric order and therefore fast.
} 
$\left(s_{t}\right)$ by their effort $\left(e_{t}\right)$ and chosen output level $\left(q_{t}\right)$. For example, a lower marginal cost (as reflected by a higher $x_{t}$ ) gives managers an incentive to raise output, which in turn leads, on average, to higher sales. However, this information conveying mechanism is partially obscured by the noise term $\epsilon_{t}$. As a result, it is not optimal for outsiders to base their expectations about $\pi_{t}$ merely on $s_{t}$. Instead, a more accurate estimate can be obtained by using a Kalman filter that calculates $\pi_{t}$ on the basis of the firm's sales history, $I_{t}$.

Insiders' optimization problem can now be formulated as follows:

$$
M_{t}=\max _{q_{t+j}, e_{t+j} ; j=0 . . \infty} E_{t}\left[\sum_{j=0}^{\infty} \beta^{j}\left(\pi\left(q_{t+j}, e_{t+j}\right)-\theta E_{S, t+j}\left[\pi\left(q_{t+j}, e_{t+j}\right)\right]\right)\right]
$$

where $\pi\left(q_{t+j}, e_{t+j}\right) \equiv q_{t+j}-\frac{1}{2} \frac{q_{t+j}^{2}}{x_{t+j}}-\frac{1}{2} c e_{t+j}^{2}$. Solving this problem gives the following proposition:

Proposition 2 The insiders' optimal production plan and effort level are given by:

$$
q_{t}=H x_{t}=H q_{t}^{o} \quad \text { and } \quad e_{t}=\frac{H^{2} B}{2 c(1-\beta A)}=H^{2} e^{o} \equiv e \quad \text { for all } t
$$

Payout to outside shareholders equals a fraction $\theta$ of reported income: $d_{t}=\theta \hat{\pi}_{t}$ where

$$
\begin{aligned}
\hat{\pi}_{t} & =\left(H-\frac{H^{2}}{2}\right) \hat{x}_{t}-\frac{1}{2} c e^{2}, \\
\text { and where } \hat{x}_{t} & =\left(A \hat{x}_{t-1}+B e_{t}\right) \lambda+K s_{t} \\
& =\frac{\lambda B e}{1-\lambda A}+K \sum_{j=0}^{\infty}(\lambda A)^{j} s_{t-j} .
\end{aligned}
$$

$H$ is the positive root to the equation:

$$
f(H) \equiv H^{2} K\left(\frac{\theta}{2}-\beta A\right)+H[\beta A(1+K)-1-\theta K]+1-\beta A=0
$$

with $K \equiv \frac{H P}{H^{2} P+R}, \lambda \equiv(1-K H)$ and $P$ is the positive root of the equation:

$$
P=A^{2} P-\frac{A^{2} H^{2} P^{2}}{H^{2} P+R}+Q .
$$

The error of outsiders' income estimate $\left(\pi_{t}-\hat{\pi}_{t}\right)$ is normally distributed with mean zero (i.e., $E_{S, t}\left[\pi_{t}-\hat{\pi}_{t}\right]=0$ ) and variance $\hat{\sigma}^{2} \equiv E_{S, t}\left[\left(\pi_{t}-\hat{\pi}_{t}\right)^{2}\right]=\left(H-\frac{H^{2}}{2}\right)^{2} P$. 
The proposition describes a rational expectations equilibrium where outsiders infer an estimate $\hat{\pi}_{t}=E_{S, t}\left[\pi_{t} \mid I_{t}\right]$ for current income $\pi_{t}$ on the basis of $I_{t}$, the history of current and past sales. Insiders take this expectation building mechanism as given. When setting $q_{t}$ and $e_{t}$ insiders know their choice will affect sales and therefore outsiders' expectations of current and future income. A rational expectations equilibrium is obtained by ensuring that insiders' optimal production and effort policy is consistent each period with the way outsiders form their expectations about income. In other words, outsiders' expectations are rational given insiders' effort and output policy, and insiders' effort and output policy are optimal given outsiders' expectations.

Since $s_{t}=q_{t}+\epsilon_{t}$ the proposition implies that sales are an imperfect (noisy) measure of the latent variable $x_{t}$, as is clear from the following "measurement equation":

$$
s_{t}=H x_{t}+\epsilon_{t} \text { with } \epsilon_{t} \sim N(0, R)
$$

Outsiders know the variance $R$ of the noise, $\epsilon_{t}$, and the parameters $A, B$ and $Q$ of the "state equation":

$$
x_{t}=A x_{t-1}+B e_{t}+w_{t-1} \text { with } w_{t} \sim N(0, Q) \text { for all } t
$$

Using the Kalman filter (see appendix), the measurement equation can be combined with the state equation to make inferences about $x_{t}$ on the basis of current and past observations of $s_{t}$. This allows outsiders to form an estimate of actual income $\pi_{t}$.

The proposition is formulated in terms of the steady state or "limiting" Kalman filter. One can show (see appendix) that the steady state estimator for $x_{t}$ is given by:

$$
\hat{x}_{t} \equiv E_{S t}\left[x_{t}\right]=\left(A \hat{x}_{t-1}+B e\right) \lambda+K s_{t}
$$

where $\lambda$ and $K$ are as defined in the proposition. $\mathrm{K}$ is called the "Kalman gain" and it plays a crucial role in the updating process. In the absence of measurement errors $x_{t}$ can be inferred with perfect precision because $\hat{x}_{t}=K s_{t}=s_{t} / H$ if $R=0$.

Substituting $\hat{x}_{t-1}$ in (18) by its estimate, one obtains after repeated substitution:

$$
\begin{aligned}
\hat{x}_{t} & =B e \lambda\left[1+\lambda A+\lambda^{2} A^{2}+\lambda^{3} A^{3}+\ldots\right]+K\left[s_{t}+\lambda A s_{t-1}+\lambda^{2} A^{2} s_{t-2}+\lambda^{3} A^{3} s_{t-3}+\ldots\right] \\
& =\frac{B e \lambda}{1-\lambda A}+K \sum_{j=0}^{\infty} \lambda^{j} A^{j} s_{t-j} .
\end{aligned}
$$

Thus, outsiders' estimate of current actual income is not only determined by their observation of current sales but also by the whole history of past sales. The weight 
$K \lambda^{j} A^{j}$ that is put on past sales levels declines, however, with time because $\lambda A<1$. The important implication is that the insiders' optimization problem is no longer static in nature but inter-temporal and dynamic. Indeed, the current production decision not only affects insiders' current expected income but also all future income.

\subsection{Production and Effort Policy}

Consider next the firm's output and effort policy. We know from Proposition 2 that insiders' optimal production and effort policies are given by, respectively, $q_{t}=H x_{t}$ and $e_{t}=H^{2} e^{o}$, where $H$ is the solution to equation (14). There exists a unique positive (real) root for $H$ which lies in the interval $\left.[0,1]\right|^{19}$ We therefore obtain the following corollary.

Corollary 2 If outsiders indirectly infer income from sales $\left(s_{t}\right)$ then insiders underproduce (i.e., $q_{t}=H x_{t}=H q_{t}^{o} \leq q_{t}^{0}$ ) and under-invest in effort (i.e., $e_{t}=H^{2} e^{o} \leq$ $\left.e^{o}\right)$.

Insiders underproduce because outsiders do not observe $x_{t}$ directly but estimate its value indirectly from sales. This gives insiders an incentive to manipulate sales (engage in "signal-jamming") in an attempt to "fool" outsiders. In particular, insiders trade off the benefit from lowering outsiders' expectations about income against the cost of underproduction. From Proposition 2 it follows that a marginal decrease in current output (and therefore expected sales) lowers outsiders' beliefs about current income by $\left(H-\frac{H^{2}}{2}\right) K$, and about income $j$ periods from now by $\left(H-\frac{H^{2}}{2}\right) K(\lambda A)^{j}$. At the first-best output level insiders' expected marginal change in realized income from cutting output is zero (since $\frac{\partial E_{t-1}\left[\pi_{t}\right]}{\partial q_{t}}=0$ at $\left.q_{t}^{o}\right){ }^{20}$ Therefore, a marginal cut in output benefits insiders. Insiders keep cutting output up to the point where the marginal

\footnotetext{
${ }^{19}$ Indeed $f(0)=-1+\beta A<0$ and $f(1)=\frac{\theta K}{2} \geq 0$. Since $\theta, A, \lambda$ and $\beta$ all fall in the $[0,1]$ interval, an exhaustive numerical grid evaluation can be executed for all possible parameter combinations. Numerical checks reveal that $H$ is the unique positive root.

${ }^{20} E_{t-1}\left[\pi_{t}\right]$ denotes insiders' expectation of $\pi_{t}$ on the basis of the information available at $t-1$. The expectation is taken with respect to $\epsilon_{t}$ only, because $w_{t-1}$ (and therefore $x_{t}$ ) is known to insiders when they implement $q_{t}$ and $e_{t}$.
} 
cost of cutting (in terms of realized income) equals the marginal benefit (in terms of lowering outsiders' expectations) ${ }^{21}$

Underproduction translates into too low effort. The production inefficiency magnifies the effect of asymmetric information on effort because the production coefficient $H$ is squared, i.e., $e_{t}=H^{2} e^{o}$. The direct, instantaneous adverse effect of asymmetric information is therefore more severe on effort than on output. This comparison ignores, however, the indirect, inter-temporal negative feedback of effort on output. Since output depends on the level of $x_{t}$, and since less effort feeds back into $x_{t}$ over time, lack of effort further undermines production over time. Suppose, for example, we start from a level $x_{t-1}$. Under the first-best and actual policies for production and effort the values for $q_{t}^{o}$ and $q_{t}$ are, respectively:

$$
\begin{aligned}
& q_{t}^{o}=1\left[A x_{t-1}+B e^{o}+w_{t-1}\right]+\epsilon_{t}, \text { and } \\
& q_{t}=H\left[A x_{t-1}+B H^{2} e^{o}+w_{t-1}\right]+\epsilon_{t} .
\end{aligned}
$$

Therefore:

$$
q_{t}^{o}-q_{t}=\left(A x_{t-1}+w_{t-1}\right)(1-H)+B e^{o}\left(1-H^{3}\right) .
$$

The negative feedback from suboptimal effort into production over one period equals $B e^{o}\left(1-H^{3}\right)$. The unconditional long-run mean for $q_{t}$ under the first-best and actual effort policies are, respectively, $E\left[q_{t}^{o}\right]=E\left[x_{t}^{o}\right]=B e^{o} /(1-A)$ and $E\left[q_{t}\right]=H E\left[x_{t}\right]=$ $B H^{3} e^{o} /(1-A)$. Given that $H$ enters in a cubic fashion, the total (instantaneous plus intertemporal) loss in output is therefore substantial (see the discussion of figure 1 below for further details). Lost output, in turn, translates into a loss of income. The unconditional mean income under the first-best and actual production policies are, respectively, given by $E\left[\pi_{t}^{o}\right]=\frac{1}{2}\left(E\left[x_{t}^{o}\right]-c e^{o 2}\right)$ and $E\left[\pi_{t}\right]=\left(H-\frac{H^{2}}{2}\right) E\left[x_{t}\right]-\frac{1}{2} c e_{t}^{2}$.

\footnotetext{
${ }^{21}$ Note that outsiders are not fooled by insiders' signal-jamming. Outsiders correctly anticipate this manipulation and incorporate it into their expectations. In spite of being unable to fool outsiders, insiders are "trapped" into behaving myopically. The situation is analogous to what happens in a prisoner's dilemma. The preferred cooperative equilibrium would be efficient production by insiders and no conjecture of manipulation by outsiders. This can, however, not be sustained as a Nash equilibrium because insiders have an incentive to underproduce whenever outsiders believe the efficient production policy is being adopted (see e.g. Stein (1989) for further details; a similar type of signaljamming equilibrium is also described in different contexts by Milgrom and Roberts (1982) and Gal-Or (1987), among others).
} 
Interestingly, the noisier the link between sales and the latent cost variable, the less outsiders can infer from sales. This reduces insiders' incentives to underproduce. The link between $s_{t}$ and $x_{t}$ can become noisier for two reasons. First, an increase in the variance of the transitory measurement errors obviously obscures the link between $s_{t}$ and $x_{t}$. Second, a decrease in the variance of the latent cost variable also weakens this link, because the measurement errors become larger relative to the variance of the latent cost variable. This leads to the following corollary.

Corollary 3 The noisier the link between the latent variable $\left(x_{t}\right)$ and its observable proxy $\left(s_{t}\right)$, the weaker insiders' incentive to manipulate the proxy by underproducing. In particular, insiders' production and effort decisions converge to the first-best ones as the variance of measurement errors becomes infinitely large $(R \rightarrow \infty)$ and as uncertainty with respect to the latent variable $x_{t}$ decreases $(Q \rightarrow 0)$, i.e., $\lim _{Q \rightarrow 0} H=\lim _{R \rightarrow \infty} H=$ 1 and $\lim _{Q \rightarrow 0} e_{t}=\lim _{R \rightarrow \infty} e_{t}=e^{o}$. Conversely, the more precise the link between $s_{t}$ and $x_{t}$, the higher the incentive to underproduce. The lower bound for $H$ and $e_{t}$ is achieved for the limiting cases $Q \rightarrow \infty$ and $R \rightarrow 0$, i.e., $\lim _{Q \rightarrow \infty} H=\lim _{R \rightarrow 0} H=$ $1-\frac{\theta}{2-\theta}$ and $\lim _{Q \rightarrow \infty} e_{t}=\lim _{R \rightarrow 0} e_{t}=\left(1-\frac{\theta}{2-\theta}\right)^{2} e^{o}$.

When $x_{t}$ becomes deterministic $(Q=0)$ then the estimation error with respect to $x_{t}$, goes to zero (i.e., $P \rightarrow 0$ ). This means that the Kalman gain coefficient $K$ becomes zero too (there is no learning). But if there is no learning $(K=0$ and $\lambda=1)$ then insiders' output decision $q_{t}$ no longer affects outsiders' estimate of the cost variable, as illustrated by equation (19). As a result the production policy becomes efficient (i.e., $H=1$ and $\left.q_{t}=x_{t}\right)$, which leads to the efficient level of effort $\left(e_{t}=H^{2} e^{o}=e^{o}\right)$.

Similarly, if there are measurement errors then the link between sales and the latent cost variable becomes noisy. This mitigates the under-investment problem, because the noise "obscures" or "hides" insiders' actions and therefore their incentive to cut production. Specifically, when the variance of the noise becomes infinitely large $(R \rightarrow$ $\infty)$ then we get the efficient outcome $(H=1)$. The reason is that sales become such a noisy measure of actual output that outsiders cannot learn anything about the realization of the latent cost variable (i.e., $K=0$ and $\lambda=1$ ). This, in turn, cuts the link between the current output decision and outsiders' expectation about current and future income. This leads to the surprising result that less informative output (and 
therefore less informative income) encourage insiders to act more efficiently.

In the absence of measurement errors $(R=0)$ the link between sales $s_{t}$ and the contemporaneous level of the latent variable $x_{t}$ becomes deterministic ${ }^{22}$ Outsiders know for sure that an increase in sales results from a fall in marginal costs. Therefore, when observing higher sales, outsiders want higher payout. In an attempt to "manage" outsiders' expectations downwards, insiders underproduce. We get the efficient outcome $(H=1)$ only if insiders get all the income $(\theta=0)$; otherwise we get under-investment $(H<1)$. As the insiders' stake of income goes to zero $(\theta \rightarrow 1)$ also production and effort go to zero (i.e., $H \rightarrow 0$ ). This result is in sharp contrast with the symmetric information case where the efficient outcome is obtained no matter how small the insiders' share of the income. Furthermore, since $H=0$ and since $\epsilon_{t} \sim N(0,0)$, it follows that sales, output and effort become zero, i.e., $s_{t}=H x_{t}+\epsilon_{t}=0$ and $e_{t}=0$. In other words, insiders put in zero effort and the firm stops producing altogether. Both outsiders and insiders get nothing, even though the firm could be highly profitable ${ }^{23}$

This result shows that for firms where insiders have a very small ownership stake (e.g. public firms with a highly dispersed ownership structure) asymmetric information and the resulting indirect inference-making process by outsiders could undermine the firm's very existence. We return to this issue and its solution in section 3 .

Figure 1 illustrates the effect of the key model parameters $(R, Q, A$ and $\theta)$ on production efficiency ${ }^{24}$ Efficiency is measured with respect to 3 different variables: effort $\left(e_{t}\right)$, the unconditional mean output $\left(E\left[q_{t}\right]\right)$, and unconditional mean income $\left(E\left[\pi_{t}\right]\right)$. The degree of efficiency is determined by comparing the actual outcome with the first-best outcome, i.e., $e_{t} / e^{o}$ (solid line), $E\left[q_{t}\right] / E\left[q_{t}^{o}\right]$ (dashed line), and $E\left[\pi_{t}\right] / E\left[\pi_{t}^{o}\right]$

\footnotetext{
${ }^{22}$ For $R=0$ we get $P=Q, K=1 / H$ and $\lambda=0$. Therefore, from Proposition 2 it follows that $\hat{x}_{t}=s_{t} / H$ and $s_{t}=H x_{t}$. Consequently, $\hat{x}_{t}=x_{t}$.

${ }^{23}$ Formally, to analyze the behavior of $H$ for $R=0$ as a function of $\theta$, we calculate:

$$
\frac{\partial H}{\partial \theta}=-\frac{2}{(2-\theta)^{2}}<0 \text { and } \quad \frac{\partial^{2} H}{\partial \theta^{2}}=-\frac{4}{(2-\theta)^{3}}<0
$$

It follows that $H$ is a concave declining function of $\theta$ when $R=0$. In other words, $H$ declines at an increasing rate. This implies that the production and effort policies become more inefficient at an increasing rate as insiders' ownership stake is eroded.

${ }^{24}$ The baseline parameter values used to generate all the figures in this paper are: $A=0.8, B=1$, $c=1, Q=4, R=1, \beta=0.95$ and $\theta=0.8$.
} 
(dotted line).

The figure shows that the efficiency loss is always largest with respect to output and smallest with respect to effort, with income falling in between because the loss in revenues is to some extent offset by lower costs of effort and production. Panel A and $\mathrm{B}$ confirm that full efficiency is achieved as $R$ moves towards $\infty$ and for $Q=0$. Panel $\mathrm{C}$ shows that a higher autocorrelation in marginal costs substantially reduces efficiency because it allows outsiders to infer more information about the latent cost variable from sales and therefore gives insiders stronger incentives to distort production.

Finally, panel D shows that production is fully efficient if outsiders have no stake in the firm's income (i.e., $\theta=0$ ). Efficiency severely declines as outsiders' stake increases. For $\theta=1$, insiders have no real ownership stake in the firm but they are still expected to determine production policy and to pay out the expected income. We know from our earlier analysis that insiders stop producing altogether if sales are fully informative (i.e., $H=0$ if $R=0$ or $Q=\infty$ ). However, if sales are not fully informative (as is the case for our benchmark parameter values), then this leaves some scope for insiders to "hide" their actions. Insiders therefore still benefit to some degree by putting in a bit of effort. For our baseline parameter values insiders' incentives are seriously eroded as they put in only $13 \%$ of the first-best effort level and achieve only $5 \%$ of the first-best output level for $\theta=1$. However, one can show that as $Q / R \rightarrow 0$ incentives are fully restored, and the first-best outcome can be achieved even for $\theta=1$. This confirms that the root cause of underproduction is the process of indirect inference and not the outside ownership stake per se. The firm's ownership structure serves, however, as a transmission mechanism through which inefficiencies can be amplified.

\subsection{The time-series properties of income}

Proposition 2 also allows us to derive the time-series properties of income:

Proposition 3 The firm's "actual income" is:

$$
\pi_{t}=h x_{t}-\frac{1}{2} c e^{2}
$$


The firm's "reported income" is described by the following target adjustment model.

$$
\begin{aligned}
\hat{\pi}_{t} & =E_{S, t}\left[\pi_{t}\right]=h \hat{x}_{t}-\frac{1}{2} c e^{2} \\
& =\hat{\pi}_{t-1}+(1-\lambda A)\left(\pi_{t}^{*}-\hat{\pi}_{t-1}\right) \\
& =\lambda A \hat{\pi}_{t-1}+K H\left(1-\frac{H}{2}\right) s_{t}+k \equiv \hat{\gamma}_{0}+\hat{\gamma}_{1} s_{t}+\hat{\gamma}_{2} \hat{\pi}_{t-1} .
\end{aligned}
$$

The "income target" $\pi_{t}^{*}$ is given by:

$$
\pi_{t}^{*}=\frac{k}{1-\lambda A}+\left(\frac{K H}{1-\lambda A}\right)\left(1-\frac{H}{2}\right) s_{t} \equiv \gamma_{0}^{*}+\gamma_{1}^{*} s_{t} .
$$

where $k \equiv h \lambda B e-\frac{1}{2} c e^{2}(1-\lambda A)$ and where $h \equiv\left(H-\frac{H^{2}}{2}\right)$. The speed of adjustment coefficient is given by $S O A \equiv(1-\lambda A)$ with $0<S O A \leq 1$.

The proposition characterizes three types of income: the "income target" $\left(\pi_{t}^{*}\right)$, "reported income" $\left(\hat{\pi}_{t}\right)$ and "actual income" $\left(\pi_{t}\right)$. Reported income follows a target that is determined by the contemporaneous level of sales. However, as equation 26 shows, the reported income only gradually adjusts to changes in sales because the SOA coefficient $(1-\lambda A)$ is less than unity. This leads to income smoothing in the sense that the effect on reported income of a shock to sales is distributed over time. In particular, a dollar increase in sales leads to an immediate increase in reported income of only $\left(H-\frac{H^{2}}{2}\right) K$. The lagged incremental effects in subsequent periods are given by $\left(H-\frac{H^{2}}{2}\right) K \lambda A$, $\left(H-\frac{H^{2}}{2}\right) K(\lambda A)^{2},\left(H-\frac{H^{2}}{2}\right) K(\lambda A)^{3}, \ldots$ The long-run effect of a dollar increase in sales on reported income equals $\left(H-\frac{H^{2}}{2}\right) K \sum_{j=0}^{\infty}(\lambda A)^{j}=\frac{\left(H-\frac{H^{2}}{2}\right) K}{1-\lambda A}$, which is the slope coefficient $\gamma_{1}^{*}$ of the income target $\pi_{t}^{*}$ (see equation (28)). In contrast, with symmetric information, the impact of a shock to sales is fully impounded into reported income immediately.

Our model for reported income can also be expressed as a distributed lag model in which reported income is a function of current and past sales. Indeed, repeated backward substitution of equation (27) gives:

$$
\hat{\pi}_{t}=\frac{k}{1-\lambda A}+K h \sum_{j=0}^{\infty}(\lambda A)^{j} s_{t-j} .
$$

Given that (i) reported income is smooth relative to actual income and (ii) payout is based on reported income, it follows that insiders soak up the variation. We return to this issue in Section 2.4, where we discuss payout. 


\section{$2.3 \quad$ Income smoothing}

We now consider the smoothing mechanism in more detail. Our model identifies two types of shocks: value-irrelevant transitory measurement errors $\left(\epsilon_{t}\right)$ and value-relevant persistent shocks to marginal costs $\left(w_{t}\right)$. We now explore in turn the effect of each type of shock on the various income measures.

\subsubsection{Transitory measurement errors}

The following corollary summarizes the effects of measurement errors.

Corollary 4 Measurement errors create asymmetric information, which in turn leads to smoothing of reported income. The effect of a measurement error $\epsilon_{t}$ on actual income $\left(\pi_{t}\right)$, reported income $\left(\hat{\pi}_{t}\right)$ and the income target $\left(\pi_{t}^{*}\right)$ is as follows:

$$
\begin{aligned}
\frac{\partial \pi_{t+j}}{\partial \epsilon_{t}} & =0 \text { for all } j \geq 0 \\
\frac{\partial \hat{\pi}_{t+j}}{\partial \epsilon_{t}} & =K h(\lambda A)^{j} \quad \text { for all } j \geq 0 \\
\frac{\partial \pi_{t+j}^{*}}{\partial \epsilon_{t}} & =\frac{K h \delta_{j}}{1-\lambda A} \text { where } \delta_{j}=1 \text { if } j=0 \text { and } \delta_{j}=0 \text { if } j>0 \\
\sum_{j=0}^{\infty} \frac{\partial \pi_{t+j}^{*}}{\partial \epsilon} & =\frac{\partial \pi_{t}^{*}}{\partial \epsilon_{t}}=\frac{K h}{1-\lambda A}=\sum_{j=0}^{\infty} \frac{\partial \hat{\pi}_{t+j}}{\partial \epsilon_{t}}
\end{aligned}
$$

Measurement errors are not value-relevant and therefore do not affect actual income (i.e., $\frac{\partial \pi_{t+j}}{\partial \epsilon_{t}}=0$ ). Measurement errors do affect outsiders' beliefs about income and therefore also reported income. Their effect is, however, distributed over time, i.e., reported income smooths out transitory measurement errors. In contrast, the income target instantaneously impounds the aggregate effect of measurement errors (i.e., $\frac{\partial \pi_{t}^{*}}{\partial \epsilon_{t}}=$ $\left.\sum_{j=0}^{\infty} \frac{\partial \hat{\pi}_{t+j}}{\partial \epsilon_{t}}\right)$. Since measurement errors are value-irrelevant noise and merely affect current sales there is no reason why they should affect future income targets. The presence of measurement errors (and therefore asymmetric information) is a necessary condition to have income smoothing. ${ }^{25}$

\footnotetext{
${ }^{25}$ Formally, $\lambda \geq 0 \Longleftrightarrow R \geq 0$. If $R=0$ then $S O A=1$ and reported income fully adjust each period to the target. Full adjustment also occurs if the marginal cost variable is uncorrelated, even
} 


\subsubsection{Persistent shocks to marginal costs.}

The following corollary summarizes the effects of persistent shocks to the marginal cost variable $x_{t}$.

Corollary $\mathbf{5}$ The effect of a persistent shock $w_{t-1}$ in the latent cost variable on actual income $\left(\pi_{t}\right)$, reported income $\left(\hat{\pi}_{t}\right)$ and the income target $\left(\pi_{t}^{*}\right)$ is as follows:

$$
\begin{aligned}
\frac{\partial \pi_{t+j}}{\partial w_{t-1}} & =h A^{j} \\
\frac{\partial \hat{\pi}_{t+j}}{\partial w_{t-1}} & =\frac{K h H A^{j}\left(1-\lambda^{j+1}\right)}{(1-\lambda)} \\
\frac{\partial \pi_{t+j}^{*}}{\partial w_{t-1}} & =\left(\frac{K H}{1-\lambda A}\right) h A^{j} \\
\sum_{j=0}^{\infty} \frac{\partial \pi_{t+j}^{*}}{\partial w_{t-1}} & =\frac{K H h}{(1-\lambda A)(1-A)}=\sum_{j=0}^{\infty} \frac{\partial \hat{\pi}_{t+j}}{\partial w_{t-1}}
\end{aligned}
$$

A persistent shock to income arises from a shock to the firm's marginal cost of production, and affects both contemporaneous and future income $\left(\frac{\partial \pi_{t+j}}{\partial w_{t-1}}=h A^{j}\right)$ because the marginal cost variable is autoregressive $(A>0)$. The cumulative effect on actual income of a persistent shock equals $\sum_{j=0}^{\infty} \frac{\partial \pi_{t+j}}{\partial w_{t-1}}=\frac{h}{1-A}$. In terms of targets, a persistent shock affects all future income targets due to the autoregressive nature of marginal production costs. And, with regard to reported income, the effect of a persistent shock is smoothed over time because in the short run outsiders cannot distinguish between measurement error and shocks to the latent cost variable. As time passes, it becomes gradually clear whether a shock in sales was due to measurement error or a change in the latent marginal cost variable. Therefore, the total aggregate effect on reported income adds up to the total effect on the income target. In other words, although reported income initially adjust more slowly than the income target, reported income "catches up" eventually so that over the long run it impounds the full aggregate effect.

The SOA to the income target decreases as $Q$, the variance of persistent shocks $w_{t}$, decreases. As $Q \rightarrow 0, K$ converges to 0 , and therefore $\lambda$ converges to 1 , and $S O A \rightarrow 1-A$. From Proposition 3 , it follows that reported income no longer depend if there is transitory noise (i.e., $S O A=1$ if $A=0$ ). And, when the variance of measurement errors becomes infinite, the SOA converges to $1-A$. 
on sales. In other words, outsiders do not learn from sales because the dynamic behavior of the latent cost variable is deterministic and fully known to outsiders.

\subsubsection{The effect of information asymmetry on income smoothing}

Corollary 6 A lower degree of information asymmetry (i.e., $R$ falls relative to $Q$ ) leads to less smoothing. In the limit (i.e., $R=0$ or $Q \rightarrow \infty$ ) both reported income and target income coincide with actual income at all times (i.e., $\pi_{t}=\hat{\pi}_{t}=\pi_{t}^{*}$ for all $\left.t\right){ }^{26}$

No smoothing whatsoever occurs when $R=0$ because in that case all information asymmetry is eliminated. In the absence of measurement errors, it is possible to infer the marginal cost variable $x_{t}$ with $100 \%$ accuracy from the observed sales figure $s_{t}$. The same result obtains when $Q \rightarrow \infty$ because in that case measurement errors are negligibly small compared to the variance of the latent cost variable. This important result confirms again that asymmetric information and not uncertainty per se is the root cause of income smoothing.

The corollary also confirms that as the degree of information asymmetry goes to zero, our rational expectations equilibrium converges to the simple sharing rule that prevails under symmetric information. Indeed: $\lim _{R \rightarrow 0} d_{t}=\theta \lim _{R \rightarrow 0} \hat{\pi}_{t}=\theta \pi_{t}$.

Consider now the other polar case where sales are extremely noisy measures of the latent cost variable (i.e., $R \rightarrow+\infty$ ). One can verify that reported income now evolve according to an $\mathrm{AR}(1)$ process:

$$
\hat{\pi}_{t}=A \hat{\pi}_{t-1}+\frac{B e}{2}-\frac{1}{2} c e^{2}(1-A)
$$

Therefore, in this case, reported income evolves according to the (expected value of the) $\mathrm{AR}(1)$ process for the latent cost variable. Sales no longer provide any additional information and measurement errors no longer affect reported income.

A similar result applies when the process for the latent cost variable becomes deterministic $(Q=0)$. One can verify that in that case the process for reported income is

\footnotetext{
${ }^{26}$ For $R=0$ we obtain $K=1 / H$ and $\lambda=0$, and as a result, we get $\hat{\gamma}_{1}=\gamma_{1}^{*}=-\frac{1}{2} c e^{2}$ and $\hat{\gamma}_{0} s_{t}=\gamma_{1}^{*} s_{t}=h x_{t}$, and therefore $\pi_{t}=\hat{\pi}_{t}=\pi_{t}^{*}$.
} 
again described by (38). Since $x_{t}$ is deterministic, its evolution can be described with $100 \%$ accuracy. Sales again become irrelevant towards determining reported income and, as a result, measurement errors play no role. This leads to the following corollary:

Corollary 7 If measurement errors become extremely large $(R=+\infty)$ or if there are no persistent shocks to the latent cost variable $(Q=0)$ then reported income behaves according to (the expected value of) the process for the latent cost variable. Sales figures do not affect reported income.

\subsubsection{Real versus financial smoothing.}

Figure 2 illustrates and summarizes the effect of the main model parameters $(\theta, A, R$ and $Q$ ) on the speed of adjustment (SOA) of reported income to the income target. Recall that no smoothing (i.e., $S O A=1$ ) occurs under symmetric information. Our symmetric information benchmark case corresponds therefore with $S O A=1$ (represented by a solid horizontal line at $S O A=1$ in the figure). The dotted line plots the SOA that results from the actual production policy (as determined by $H$ ) derived under asymmetric information. While this gives us an idea of the total amount of intertemporal income smoothing, it does not tell us how much of this is due to the suboptimal production policy that results from indirect inference and how much is due to mere financial smoothing that results from asymmetric information. We refer to the former as "real" smoothing and to the latter as "financial" smoothing.

The financial smoothing component is measured by evaluating the SOA at the first-best production policy $H=1$, i.e., $S O A=1-A \lambda[H=1]$ (as represented by the dashed line). Therefore $A \lambda[H=1]$ reflects the amount of smoothing that would take place under asymmetric information but assuming that insiders were to adopt the efficient production policy. Financial smoothing is therefore measured in figure 2 by the distance between the horizontal solid line at $\mathrm{SOA}=1$ and the dashed line. Since the dotted line represents the total amount of smoothing (i.e., financial plus real smoothing), the difference between the dashed line and the dotted line (given by $A \lambda-A \lambda[H=1])$ captures the amount of "real smoothing". 
The distinction between the two types of smoothing is clearly illustrated in panel A which plots the SOAs as a function of the (real) outside ownership stake $\theta$. Changing $\theta$ does not alter the degree of asymmetric information between insiders and outsiders and, as a result, the amount of financial smoothing remains constant. The corresponding SOA of 0.86 (dashed line) implies a half-life of about 0.35 years for adjustment of reported income to changes in sales ${ }^{27}$ Increasing $\theta$ introduces, however, additional real smoothing and this reduces the SOA from 0.86 (for $\theta=0$ ) to 0.56 (for $\theta=1$ ) corresponding, respectively, to a half-life of 0.35 years and 0.84 years. In the latter case real smoothing adds about half a year to the half-life. The plot confirms our earlier results that reducing inside ownership leads to severe underproduction, which in turn leads to a smoother reported income flow because income becomes less sensitive to sales.

Panel B shows that smoothing also increases with the degree of autocorrelation in the latent cost variable. No intertemporal smoothing takes place when $A=0$ because in that case current and past realizations of $x_{t}$ are irrelevant for the future. As a result, insiders' private information about $x_{t}$ is also irrelevant for the future. Note that higher autocorrelation raises both real and financial smoothing substantially.

Finally, panels $\mathrm{C}$ and $\mathrm{D}$ confirm that the total amount of smoothing increases with the degree of information asymmetry (as reflected by a higher $R$ or lower $Q$ ). Paradoxically, more intertemporal smoothing coincides with higher production efficiency (see figure 1): when outsiders can infer less from sales, there is also less of an incentive to manipulate production. Note that a higher degree of information asymmetry unambiguously increases the amount of financial smoothing.

\subsection{Payout Policy}

Since the payout to outsiders is given by $d_{t}=\theta \hat{\pi}_{t}$, it follows that the firm's payout policy to outsiders is described by the target adjustment model for $\hat{\pi}_{t}$ in (27):

$$
d_{t}=\lambda A d_{t-1}+\theta h K s_{t}+\theta k .
$$

\footnotetext{
${ }^{27}$ Half-life is the time needed to close the gap between reported income and the income target by $50 \%$, after a one-unit shock to the error term in the target adjustment model for reported income. When reported income follows an $\mathrm{AR}(1)$ process half-life is $\log (0.5) / \log (1-S O A)$.
} 
The payout model is similar to the well known Lintner (1956) dividend model. The key difference is that in Lintner (1956) the payout target is determined by the firm's net income, whereas in our model the target is a function of sales because net income is not directly observable by outsiders. Payout in our model is not smoothed relative to reported income but relative to a proxy variable observable by outsiders, i.e., sales ${ }^{28}$

\section{Robustness, extensions and discussion}

\subsection{Forced disclosure and the "big bath"}

Insiders' payout policy guarantees that the capital market constraint is satisfied at all times, i.e., $S_{t} \geq \varphi \alpha E_{t}\left[V_{t} \mid I_{t}\right]$. But will insiders be willing to adhere to this payout policy under all circumstances? Insiders' participation constraint is satisfied if they are better off paying out than triggering collective action. Collective action implies that stockholders "open up" the firm and uncover its true value $\left(V_{t}\right)$. It is reasonable (although not necessary) to assume that collective action also imposes a cost upon insiders. Graham et al. (2005) report that the consequences of missing an earnings target can be so serious for managers' career and reputation that they try to avoid missing the target at all cost. Without loss of generality assume that these costs are proportional to the firm value and given by $C_{t}=c V_{t}$.

Insiders trigger collective action when outsiders' beliefs regarding the firm's value (and therefore the required payout) are excessively overoptimistic. "Forced disclosure" by outsiders pricks the bubble that has been building up over time and brings outsiders' beliefs about the firm value back to reality, i.e., $E_{t}\left[V_{t} \mid I_{t}\right]=V_{t}$.

A sufficient (but not necessary) condition for insiders to keep paying out according

\footnotetext{
${ }^{28}$ Payout smoothing in the strict Lintner sense could be obtained, for instance, if insiders are riskaverse and subject to habit formation. Lambrecht and Myers (2011) show that insiders of this type smooth payout relative to income by borrowing and lending. Introducing debt and cash into our model would allow risk-averse insiders to borrow against future income or to "park" reported income onto the firm's cash account (see also footnote 12 ).
} 
to outsiders' expectations is:

$$
M_{t}=V_{t}-\varphi \alpha E_{t}\left[V_{t} \mid I_{t}\right] \geq V_{t}-\varphi \alpha V_{t}-c V_{t} \Longleftrightarrow V_{t} \geq \frac{\varphi \alpha}{\alpha \varphi+c} E_{t}\left[V_{t} \mid I_{t}\right]
$$

Outsiders have an incentive to trigger collective action if the firm's actual value $\left(V_{t}\right)$ drops sufficiently below below what outsiders believe the firm to be worth $\left(E_{t}\left[V_{t} \mid I_{t}\right]\right){ }^{29}$ This situation arises if outsiders' beliefs about the latent cost variable (as reflected by $\hat{x}_{t}$ ) are overoptimistic due to measurement errors ${ }^{30}$

As mentioned before, insiders absorb the variation between actual and reported income. In particular, each period insiders actually receive $\left(\pi_{t}-\varphi \alpha \hat{\pi}_{t}\right)$ instead of $(1-\varphi \alpha) \pi_{t}$. The net gain (or loss) to insiders is therefore $\varphi \alpha\left(\pi_{t}-\hat{\pi}_{t}\right)$. The net gain relative to the actual amount received is $\varphi \alpha\left(\pi_{t}-\hat{\pi}_{t}\right) /\left(\pi_{t}-\varphi \alpha \hat{\pi}_{t}\right)$. For a small outside ownership stake (e.g., private firms) or a low degree of investor protection $(\alpha)$, the gain or loss that insiders absorb is only a small fraction of the income stream they receive. However, as $\varphi \rightarrow 1$ and $\alpha \rightarrow 1$, these gains $\pi_{t}-\hat{\pi}_{t}$ constitute $100 \%$ of insiders' income.

How can one reduce the likelihood of costly forced disclosure? Since a lower nominal outside ownership stake $(\varphi)$ and a lower degree of investor protection $(\alpha)$ relax insiders' participation constraint, one obvious solution is to reduce either of these two (or a combination of both) ${ }^{31}$ Unfortunately, this also reduces the firm's capacity to raise outside equity. Therefore, firms that rely heavily on outside equity (e.g. public firms) adopt more efficient (in terms of cost and speed) disclosure mechanisms such as voluntary audited disclosure. While "big baths" do occur in reality, they rarely result from a very costly forced disclosure process but they are much more likely to happen through the process of regular voluntary audited disclosures ${ }^{32}$ As we show below, high quality audited disclosures keep misvaluations within bounds and resolve the need for insiders

\footnotetext{
${ }^{29}$ Calculating the exact condition under which insiders optimally exercise their option to trigger collective action is beyond the scope of this paper.

${ }^{30}$ Note that measurement errors as such do not jeopardize the actual economic viability of the firm because measurement errors are value-irrelevant (even though they can induce temporary misvaluations in the firm's stock price). Therefore, in our model a "big bath" would never coincide with bankruptcy or actual abandonment by insiders because actual firm value is always strictly positive in our model.

${ }^{31}$ Non-pecuniary private benefits of control may also play a role in keeping insiders on board.

${ }^{32}$ One important exception is the case of deliberate fraud which, by its very nature, often requires legal investigative teams with special powers to uncover the truth.
} 
to trigger collective action and force disclosure. Still, in many countries with weak governance, reliable accounting information may not be available and outsiders' property rights may be hard to enforce, explaining the widespread phenomenon of family firms with a high insider ownership stake and a low degree of investor protection.

\subsection{Audited disclosure and ownership structure}

Our analysis in section 2 showed that the firm's effort and production policy become increasingly more inefficient as insiders' real ownership stake $(1-\varphi \alpha)$ decreases. This could pose serious problems for public firms, which often have a small inside equity base and a large number of highly dispersed outside shareholders. Our model predicts that under-investment could become so severe that firms stop producing altogether, even if they are inherently profitable.

It may therefore come as no surprise that mechanisms have been developed to reduce the degree of information asymmetry. In particular, publicly traded companies (unlike private firms) are subject to stringent disclosure requirements ${ }^{33}$ The traditional argument put forward to justify disclosure is often that of investor protection. The general underlying idea is that outside investors need to be protected from fraud or conflicts of interests by insiders (usually managers). Audited disclosure is generally believed to benefit outsiders by curtailing insiders' ability to exploit their informational advantage and to extract informational rents.

Our paper shows that the case for audited accounting information rests not only on investor protection. Our model shows that asymmetric information is problematic even if insider trading is precluded and outsiders' property rights are $100 \%$ guaranteed (i.e., $\alpha=1$ ). Moreover, disclosure is not necessarily a win/lose situation for outsiders/insiders. In our setting, eliminating information asymmetry would be welcomed by outsiders and insiders alike. In other words, disclosure (assuming it can be achieved in a relatively costless fashion) is a win-win situation for all parties involved.

\footnotetext{
${ }^{33}$ While a private firm has no requirement publicly to disclose much, if any, financial information, public firms are required to submit an annual form (Form 10-K in the United States, for instance) giving comprehensive detail of the company's performance. Public firms are also required to spend more on independent, certified public accountants and they are subject to much more laws and regulations (such as the Securities Act of 1933 and the 2002 Sarbanes-Oxley Act in the U.S.).
} 
Formally, in proposition 2 we showed that, on the basis of current and past sales, outsiders calculate an income estimate $\hat{\pi}_{t}$. The error of outsiders' estimate, $\pi_{t}-\hat{\pi}_{t}$, is normally distributed with zero mean and variance $\hat{\sigma}^{2}$. Suppose now that, in addition to the sales data, auditors provide each period an independent estimate $y_{t}$ of income where $y_{t} \sim N\left(\pi_{t}, \sigma^{2}\right)$. Importantly, auditors provide their assessment after $\epsilon_{t}$ and $w_{t-1}$ are realized. The auditors' estimate is unbiased (i.e., $\left.E_{t}\left[y_{t}\right]=\pi_{t}\right){ }^{34}$ but subject to some random error $\left(y_{t}-\pi_{t}\right)$. Insiders nor auditors have control over the error, and the error is independent across periods. In summary, on the basis of the full sales history $I_{t}$ outsiders construct a prior distribution of current income that is given by $N\left(\hat{\pi}_{t}, \hat{\sigma}^{2}\right)$. Auditors then provide an independent estimate $y_{t}$, which outsiders know is drawn from a distribution $N\left(\pi_{t}, \sigma^{2}\right)$.

Using simple Bayesian updating, it follows that the outsiders' estimate of income conditional on $y_{t}$ and on the sales history $I_{t}$ is given by

$$
\kappa y_{t}+(1-\kappa) \hat{\pi}_{t} \quad \text { where } \kappa=\frac{\hat{\sigma}^{2}}{\hat{\sigma}^{2}+\sigma^{2}} \text {. }
$$

The parameter $\kappa$ can be interpreted as a parameter that reflects the quality of the additional information provided. A value of $\kappa$ close to 0 means that the audited disclosure is highly unreliable and carries little weight in influencing outsiders' beliefs about income.

How does the provision of information by independent auditors influence insiders' decisions? Insiders' optimization problem can now be formulated as:

$$
\begin{aligned}
M_{t} & =\max _{q_{t+j}, e_{t+j} ; j=0 . . \infty} E_{t}\left[\sum_{j=0}^{\infty} \beta^{j}\left(\pi\left(q_{t+j}, e_{t+j}\right)-\varphi \alpha \kappa E_{t+j}\left(y_{t+j}\right)-\varphi \alpha(1-\kappa) E_{S, t+j}\left[\pi\left(q_{t+j}, e_{t+j}\right)\right]\right)\right] \\
& =\max _{q_{t+j}, e_{t+j} ; j=0 . . \infty} E_{t}\left[\sum_{j=0}^{\infty} \beta^{j}\left(\pi\left(q_{t+j}, e_{t+j}\right)(1-\varphi \alpha \kappa)-\varphi \alpha(1-\kappa) E_{S, t+j}\left[\pi\left(q_{t+j}, e_{t+j}\right)\right]\right)\right] \\
& =(1-\varphi \alpha \kappa) \max _{q_{t+j}, e_{t+j} ; j=0 . . \infty} E_{t}\left[\sum_{j=0}^{\infty} \beta^{j}\left(\pi\left(q_{t+j}, e_{t+j}\right)-G(\varphi, \alpha, \theta) E_{S, t+j}\left[\pi\left(q_{t+j}, e_{t+j}\right)\right]\right)\right]
\end{aligned}
$$

\footnotetext{
${ }^{34}$ This assumption is not strictly necessary. For example, if auditors are, say, conservative then the analysis would remain similar provided that outsiders know the auditors' bias.

${ }^{35}$ It might be possible for outsiders to refine the estimate of the latent cost variable $x_{t}$ by using the entire history of auditors' income estimates. We ignore this possibility, and assume that all relevant accounting information is encapsulated in the auditors' most recent income estimate.
} 
where $G(\varphi, \alpha, \kappa) \equiv \frac{\varphi \alpha(1-\kappa)}{1-\varphi \alpha \kappa} \equiv \frac{\theta(1-\kappa)}{1-\theta \kappa}$, and where we made use of the fact that the auditors' estimate is unbiased at all times, i.e., $E_{t+j}\left[y_{t+j}\right]=\pi\left(q_{t+j}, e_{t+j}\right)$ for all $j$, irrespective of insiders' decision rules for $q_{t+j}$ and $e_{t+j}$. In other words, insiders cannot distort auditors' estimate (the release of the accounting information happens by independent auditors after income are realized).

Comparing the optimization problem (42) with the original one we solved in (9), one can see that both problems are essentially the same, except for the fact that the outside ownership parameter $\theta$ in (9) has been replaced by the governance index $G(\varphi, \alpha, \kappa)$ in 42 . This means that the solutions for $q_{t+j}$ and $e_{t+j}$ can be obtained by merely replacing $\theta$ by $G(\varphi, \alpha, \kappa)$ in the solution we previously obtained.

$G(\varphi, \alpha, \kappa)$ ranges across the $[0,1]$ interval and can be interpreted as an (inverse) governance index that crucially depends on the outsiders' ownership stake $(\varphi)$, the degree of investor protection $(\alpha)$ and on the quality of audited disclosure $(\kappa)$. If $\kappa=0$ (i.e., $G=\theta$ ) then the independently provided accounting information is completely unreliable and discarded by outsiders. In that case the optimization problem and its solution coincide exactly with the ones presented in section 2, If $\kappa=1$ (i.e., $G=0$ ) then the independently provided accounting information is perfectly reliable. All information asymmetry is resolved and we get the first-best outcome that was presented in section 1 .

Calculating the comparative statics for $G$ with respect to $\theta$ and $\kappa$ gives:

$$
\frac{\partial G(\theta, \kappa)}{\partial \theta}=\frac{1-\kappa}{[1-\theta \kappa]^{2}} \geq 0, \quad \text { and } \quad \frac{\partial G(\theta, \kappa)}{\partial \kappa}=\frac{\theta(\theta-1)}{[1-\theta \kappa]^{2}} \leq 0 .
$$

It follows that reducing outsiders' (real) equity stake or increasing the quality of audited disclosure act in a similar fashion, and these levers are therefore substitutes. The results are summarized in the following corollary:

Corollary 8 Higher quality audited disclosure $(\kappa)$ improves the firm's operating efficiency and acts as a substitute for a higher real inside ownership stake ( $\theta)$. 


\subsection{Accounting quality, stock market size and growth}

In this section we examine the model's implications for corporate investment (and economic growth more generally) by analyzing the initial decision to set up the firm.

Assume that an investment cost $E$ is required to establish the firm at time $t=$ 0 . The financing is raised from inside and outside equity. To abstract from adverse selection issues (see Myers and Majluf (1984)) we assume as before that insiders have access to an unbiased estimate for $x_{0}$ at time zero (i.e., $\hat{x}_{0}=x_{0}$ ). As a result insiders and outsiders attach the same value $V\left(x_{0} ; \theta, \kappa\right)$ to the firm when the firm is founded, as given in the following proposition.

Proposition 4 The value of the firm at time $t=0$ is given by:

$$
V_{0}\left(x_{0} ; \theta, \kappa\right)=\frac{h}{(1-\beta A)}\left(x_{0}+\frac{B e \beta}{1-\beta}\right)-\frac{1}{2} \frac{c e^{2}}{(1-\beta)}
$$

where the values for the production $\left(h \equiv H-\frac{H^{2}}{2}\right)$ and effort (e) policies are obtained as described in proposition 2 but by replacing $\theta$ everywhere by $G(\theta ; \kappa)$.

We know that the firm value monotonically declines in the real ownership stake $\theta$ (三 $\alpha \varphi)$. Therefore the first-best firm value is achieved when the outside ownership stake is zero (i.e., $\theta=0$ ). Assuming the investment in the firm happens on a now-or-never basis at $t=0$, the first-best investment decision is given by the following criterion: invest if and only if $V\left(x_{0} ; \theta=0, \kappa\right) \geq E$. Note that the accounting quality $\kappa$ does not influence the investment decision when $\theta=0$, because without outside investors audited disclosure becomes superfluous.

Assume next, without loss of generality, that insiders have no money to contribute and need to raise the full amount $E$ from outsiders. Assume further that the quality of audited disclosure $(\kappa)$ is exogenously given, but that the real ownership stake $\theta$ can be chosen 36 The decision problem is therefore to identify the lowest value for $\theta$ that allows insiders to raise enough outside equity, $S_{t}$, to cover the investment cost (i.e., $\left.S_{0}\left(x_{0} ; \theta, \kappa\right)=E\right)$.

\footnotetext{
${ }^{36}$ Outsiders' nominal ownership stake $\varphi$ is obviously a control variable. The degree of investment protection $\alpha$ is, initially at least, under control too through the firm's charter and governance mechanisms (such as board composition) that are implemented upon the firm's foundation.
} 
Since $\hat{x}_{0}=x_{0}$, the initial inside $\left(M_{0}\right)$ and outside $\left(S_{0}\right)$ equity are:

$$
\begin{aligned}
M_{0} & =V_{0}\left(x_{0} ; \theta, \kappa\right)-\theta E_{S, 0}\left[V_{0}\left(\hat{x}_{0} ; \theta, \kappa\right)\right]=(1-\theta) V_{0}\left(x_{0} ; \theta, \kappa\right) \\
S_{0} & =\theta E_{S, 0}\left[V_{0}\left(\hat{x}_{0} ; \theta, \kappa\right)\right]=\theta V_{0}\left(x_{0} ; \theta, \kappa\right)
\end{aligned}
$$

The (constrained) optimal value for $\theta$ is therefore the solution to:

$$
\theta^{o}=\min \left\{\theta \mid \theta V_{0}\left(x_{0} ; \theta, \kappa\right)=E\right\}
$$

The solution is illustrated in Figure 3. Panel A plots the total firm value $V_{0}\left(x_{0} ; \theta, \kappa\right)$ as a function of outsiders' real ownership $\theta$ for three different levels of disclosure quality $(\kappa)$. In line with our earlier results, total firm value declines monotonically with respect to $\theta$. The loss can be substantial: the first-best firm value equals 900 (i.e., for $\theta=0$ ), whereas the firm value under $100 \%$ outside ownership equals a mere 150 (i.e., for $\theta=1$ ). High quality audited disclosure $(\kappa=0.9)$ can, however, significantly mitigate the value loss. For example for $\kappa=0.9$ the loss in value appears to be less than $1 \%$ for as long as insiders own a majority stake. In the absence of audited disclosure or when audited disclosure is completely useless (i.e., $\kappa=0$ ), significant value losses kick in at much lower outside ownership levels. For example, at $\theta=0.5$ about a third of the first-best value is lost in the absence of audited disclosure.

Panel B shows the total outside equity value as a function of the outside ownership stake for three different levels of disclosure quality. The curves resemble "outside equity Laffer curves" ${ }^{37}$ The outside equity value $\theta V_{0}\left(x_{0} ; \theta, \kappa\right)$ is an inverted U-shaped function function of $\theta$ that reaches a unique maximum. This maximum changes significantly according to the quality of the audited disclosure, and equals about 650, 420 and 310 for high quality, low quality and no audited disclosure, respectively. No investment would take place in the absence of audited disclosure, because the amount of outside equity that can be raised is inadequate to finance the investment cost (which equals $E=400$ ). Investment would take place in the two case where accounting information is audited, and about $\theta^{\circ}=45 \%\left(\theta^{o^{\prime}}=55 \%\right)$ of shares would end up in outsiders' hands with high (low) quality audited disclosure.

Our results provide theoretical support for a number of empirical studies that have found a positive link between economic growth, stock market size, stock market capitalizations, and quality of accounting information. The standard explanation for this

\footnotetext{
${ }^{37}$ The traditional Laffer curve is a graphical representation of the relation between government revenue raised by taxation and all possible rates of taxation. The curve resembles an inverted Ushaped function that reaches a maximum at an interior rate of taxation.
} 
result is that higher quality accounting information provides better investor protection. While higher investor protection (i.e., higher $\alpha$ ) also leads to higher stock market valuations in our model, audited disclosure does not as such improve investor protection in our model. Instead, independent audited disclosure reduces the inefficiencies from indirect inference because insiders are less concerned about the effect of their actions on outsiders' expectations. Our model therefore highlights an important role of independent audited disclosure and monitoring that has hitherto not been recognized in the literature ${ }^{38}$ Figure 3 illustrates that the efficiency gains from audited disclosure can be economically highly significant.

\section{Additional empirical implications}

Our theory of intertemporal income smoothing yields rich, testable implications for the time-series properties of reported income and payout to outsiders. Some of these were outlined in the introductory remarks. Here, we provide some more specific crosssectional implications:

First, asymmetric information is the key driver of income smoothing in our model. Such smoothing implies that reported income follows a target adjustment process. A testable implication is that, in the cross-section of firms, the speed of adjustment towards the income target should decrease with the degree of information asymmetry between inside and outside investors.

Second, asymmetric information and the resulting inference process also lead to underproduction by firms. Both the degree of underproduction and income smoothing should increase in the cross-section of firms as outside ownership increases. Therefore, all else equal, public firms are expected to smooth income more and they suffer more from under-investment. Kamin and Ronen (1978) and Amihud, Kamin, and Ronen (1983) show that owner-controlled firms do not smooth as much as manager-controlled

\footnotetext{
${ }^{38}$ There is, however, a dark side to monitoring that we ignore in this paper. Burkart, Gromb, and Panunzi (1997) show that monitoring and tight control by shareholders creates an ex-ante hold-up threat which reduces managerial initiative and non-contractual investment. A dispersed ownership structure dilutes the hold-up threat and this gain has to be weighed against the loss in productive efficiency due to inadequate monitoring and disclosure.
} 
firms. Prencipe, Bar-Yosef, Mazzola, and Pozza (2011) also provide direct evidence for this. They find that income smoothing is less likely among family-controlled companies than non-family-controlled companies in a set of Italian firms. The implication on under-investment is unique to our model as it implies real smoothing but to the best of our knowledge, this has not yet been thoroughly tested. There is, however, convincing survey evidence by Graham et al. (2005) that a large majority of managers are willing to postpone or forgo positive NPV projects in order to smooth earnings.

Third, since smoother income leads to smoother payout, one would expect, all else equal, that public firms also smooth payout more than private firms. This implication is consistent with Roberts and Michaely (2007) who show that private firms smooth dividends less than their public counterparts.

Fourth, income figures that are independently provided by auditors improve production efficiency because it reduces insiders' incentives to manipulate income through their production and effort policy. Thus, all else equal higher quality accounting information should increase firm productivity, managerial effort, stock market capitalization, and, more generally, economic growth (as confirmed, for instance, by Rajan and Zingales, 1998).

Finally, firms that do not have access to independent and high quality auditors can issue less outside equity. Our model therefore predicts that inside ownership stakes should be greater in countries with weaker quality of accounting information, which appears consistent with the widespread phenomenon of greater private and family firms in such countries.

\section{Related literature}

Our paper belongs to a series of papers (Fluck (1998, 1999), Myers (2000), Jin and Myers (2006) and Lambrecht and Myers $(2007,2008,2011)$ ) where insiders make payouts to avoid collective action by outsiders. With the exception of Jin and Myers (2006) these papers assume symmetric information between insiders and outsiders. In Jin and Myers, insiders pay out according to outsiders' expectations of cashflows and absorb the variation, as is also the case in our model. Their model differs, however, in a number of fundamental ways. Insiders do not make any production or effort decisions in Jin 
and Myers. Their cash-flow process is completely exogenous and contains a component that is only observable to insiders. Outsiders do not learn about the latent component and, as a result, there is no intertemporal smoothing in their model.

Our model of intertemporal smoothing by a firm's insiders also provides theoretical support for the Lintner (1956) model of smooth payout policy. To our knowledge, it is only the second model to do so after Lambrecht and Myers (2011), who assume a complete information setting where managers set payout policy and their own compensation, but there is a threat of collective action by shareholders. Risk aversion and habit formation of managers induces them to smooth rents (and, therefore also payout) relative to net income. Our model does not explain why payout is smooth relative to income, but instead explains why income is smooth in the first place. As such, our model is complementary to the one of Lambrecht and Myers (2011). Importantly, while risk aversion is a pervasive ingredient in existing papers on income and payout smoothing, our paper does not rely on risk aversion to generate intertemporal smoothing.

An early, very comprehensive discussion of the objectives, means and implications of income smoothing can be found in the book by Ronen and Sadan (1981) (which includes references to some of the earliest work on the subject). In Lambert (1984) and Dye (1988) risk-averse managers without access to capital markets want to smooth the firm's reported income in order to provide themselves with insurance ${ }^{39}$ Fudenberg and Tirole (1995) develop a model where reported income is paid out as dividends and where risk-averse managers enjoy private benefits from running the firm but can be fired after poor performance. They assume that recent income observations are more informative about the prospects of the firm than older ones. They show that managers distort reported income to maximize the expected length of their tenure: managers boost (save) income in bad (good) times.

There are also signaling and information-based models to explain income smoothing. Ronen and Sadan (1981) employ a signaling framework to argue that only firms with good future prospects smooth earnings because borrowing from the future could be disastrous to a poorly performing firm when the problem explodes in the near term.

\footnotetext{
${ }^{39}$ Models driven by risk-aversion (or limited liability) of managers naturally lead to considering optimal compensation schemes and how they affect smoothing, but we have excluded this literature for sake of brevity.
} 
Trueman and Titman (1988) also argue that managers smooth income to convince potential debtholders that income has lower volatility in order to reduce the cost of debt. Smoothing costs arise from higher taxes and auditing costs. Tucker and Zarowin (2006) provide evidence that the change in the current stock price of higher-smoothing firms contains more information about their future earnings than does the change in the stock price of lower-smoothing firms. Our model assumes that there are at least some limits to perfect signaling and is in this sense complementary to these alternative explanations for earnings smoothing ${ }^{40}$

The rational expectations equilibrium of our model works as follows. Upon observing higher sales, outsiders want higher payout. In an attempt to "fool" outsiders, insiders underproduce (resulting in real smoothing). However, outsiders anticipate this, and therefore in equilibrium insiders do not succeed in their attempt. Nevertheless, the indirect inference process distorts corporate choices. This informational effect is similar to the ones discussed (albeit in different economic settings) in Milgrom and Roberts (1982), Riordan (1985), Gal-Or (1987), Stein (1989), Holmström (1999), and more recently Bagnoli and Watts (2010) ${ }^{41}$ The learning process (which we model as a filtering problem) and the intertemporal smoothing mechanism are, however, quite different from existing papers. The inference model we consider is also fundamentally different from alternative information models in the accounting and financial economics literature in which a firm's disclosures are always fully verifiable and the firm simply chooses whether to disclose or not. Disclosure games (see, for instance, Dye (1985, 1990), and more recently, Acharya, DeMarzo and Kremer (2011)) in which insiders can

\footnotetext{
${ }^{40}$ In a slightly different approach to motivating earnings smoothing, Goel and Thakor (2003) develop a theory in which greater earnings volatility leads to a bigger informational advantage for informed investors over uninformed investors, so that if sufficiently many current shareholders are uninformed and may need to trade in the future for liquidity reasons, they want the manager to smooth reported earnings as much as possible.

${ }^{41}$ While in our model insiders have an incentive not to raise outsiders' expectations regarding income, opposite incentives arise in Bagnoli and Watts (2010) who examine the interaction between product market competition and financial reporting. They show that Cournot competitors bias their financial reports so as to create the impression that their production costs are lower than they actually are. One can think of other considerations that might encourage insiders to inflate income (e.g. if insiders wanted to issue more stock, acquire a target with a stock offer, or if insiders' contractual remuneration increases with reported income) but these are beyond the scope of this paper.
} 
send imperfect signals and alter production to affect outsiders' inference could be an interesting avenue for future research.

\section{Conclusion}

The theory of income smoothing developed in this paper assumes that (i) insiders have information about income that outside shareholders do not, but (ii) outsiders are endowed with property rights that enables them to take collective action against insiders if they do not receive a fair payout that meets their expectations. We showed that insiders report income consistent with outsiders' expectations based on available information rather than the true income. This gave rise to a theory of inter-temporal smoothing - both real and financial - in which observed income and payout adjust partially and over time towards a target and insiders under-invest in production and effort. The primary friction driving the smoothing is information asymmetry as insiders are averse to choosing actions that would unduly raise outsiders' expectations about future income. Interestingly, this problem is more severe the smaller is the inside ownership and thus should be a greater hindrance to the functioning of publicly (or dispersedly) owned firms. We show that the firm's outside equity value is an inverted U-shaped function of outsiders' ownership stake. This "outside equity Laffer curve" shows that the under-investment problem severely limits the firm's capacity to raise outside equity. However, a disclosure environment with adequate quality of independent auditing can help mitigate the problem, leading to the conclusion that accounting quality can enhance investments, size of public stock markets and economic growth.

While our theory of inter-temporal smoothing of income and payout conforms to several existing findings (such as the Lintner (1956) model of payout policy), it also leads to a range of testable empirical implications in the cross-section of firms as information asymmetry and ownership structure are varied. These are worthy of further investigation. It would also be fruitful to apply our framework to other corporate contexts so as to investigate the role of capital structure (debt versus equity) in addressing income smoothing as well as to study how alternative managerial objectives such as myopia further affect smoothing outcomes. 


\section{Appendix}

\section{Proof of Proposition 1}

The firm value is given by:

$$
V_{t}=E_{t}\left[\sum_{j=0}^{\infty} \beta^{j}\left[q_{t+j}-\frac{q_{t+j}^{2}}{2 x_{t+j}}-\frac{1}{2} c e_{t+j}^{2}\right]\right]
$$

The first order conditions with respect to $q_{t}$ and $e_{t}$ are:

$$
\begin{aligned}
& \frac{\partial V_{t}}{\partial q_{t}}=1-\frac{q_{t}}{x_{t}}=0 \\
& \frac{\partial V_{t}}{\partial e_{t}}=E_{t}\left[\frac{1}{2}\left(\frac{q_{t}}{x_{t}}\right)^{2} B+\frac{\beta}{2}\left(\frac{q_{t+1}}{x_{t+1}}\right)^{2} B A+\frac{\beta^{2}}{2}\left(\frac{q_{t+2}}{x_{t+2}}\right)^{2} B A^{2}+\ldots-c e_{t}\right]=0(49)
\end{aligned}
$$

Solving gives the expressions for $q_{t}$ and $e_{t}$ as given in the proposition.

We now check the second order condition. The first order leading principal minor of the Hessian is given by $\frac{\partial^{2} V}{\partial q_{t}^{2}}=-\frac{1}{x_{t}}<0$. The second order leading principal minor is given by:

$$
\frac{\partial^{2} V_{t}}{\partial q_{t}^{2}} \frac{\partial^{2} V_{t}}{\partial e_{t}^{2}}-\left(\frac{\partial^{2} V_{t}}{\partial e_{t} \partial q_{t}}\right)^{2}=E_{t}\left[\frac{c}{x_{t}}+\frac{B^{2}}{x_{t}}\left[\frac{\beta A^{2}}{x_{t+1}}+\frac{\beta^{2} A^{4}}{x_{t+2}}+\frac{\beta^{3} A^{6}}{x_{t+3}}+\frac{\beta^{4} A^{8}}{x_{t+4}}+\ldots\right]\right]>0
$$

The first and second order leading principal minor of the Hessian are negative and positive, respectively (assuming a positive cost variable). It follows that the Hessian is negative definite. Consequently, the critical point is a maximum.

\section{Proof of Proposition 2}

Insiders' optimization problem can be formulated as:

$$
M_{t}=\max _{\left\{q_{t+j}, e_{t+j} ; j=0 . . \infty\right\}} E_{t}\left[\sum_{j=0}^{\infty} \beta^{j}\left(\pi\left(q_{t+j}, e_{t+j}\right)-\theta E_{S, t+j}\left(\pi\left(q_{t+j}, e_{t+j}\right) \mid I_{t+j}\right)\right)\right]
$$

where $\pi\left(q_{t+j}, e_{t+j}\right)=q_{t+j}-\frac{1}{2} \frac{q_{t+j}^{2}}{x_{t+j}}-\frac{1}{2} c e_{t+j}^{2}$ and $I_{t}$ denotes the information available to outsiders at time $t$, i.e., $I_{t}=\left\{s_{t}, s_{t-1}, s_{t-2}, s_{t-3}, \ldots\right\}$. We guess the form of the solution and use the method of undetermined coefficients (and subsequently verify this conjecture). The conjectured solution for outsiders' rational expectations based on the 
information $I_{t}$ is as follows:

$$
E_{S, t}\left[\pi\left(q_{t}, e_{t}\right) \mid I_{t}\right]=b+\sum_{j=0}^{\infty} a_{j} s_{t-j}
$$

where the coefficients $b$ and $a_{j}(j=0,1, \ldots)$ remain to be determined.

The first-order conditions are:

$$
\begin{aligned}
& \frac{\partial M_{t}}{\partial q_{t}}=1-\frac{q_{t}}{x_{t}}-\theta\left(a_{0}+\beta a_{1}+\beta^{2} a_{2}+\beta^{3} a_{3}+\ldots\right)=0 \\
& \frac{\partial M_{t}}{\partial e_{t}}=E_{t}\left[\frac{1}{2}\left(\frac{q_{t}}{x_{t}}\right)^{2} B+\frac{\beta}{2}\left(\frac{q_{t+1}}{x_{t+1}}\right)^{2} B A+\frac{\beta^{2}}{2}\left(\frac{q_{t+2}}{x_{t+2}}\right)^{2} B A^{2}+\ldots-c e_{t}\right]=(554)
\end{aligned}
$$

Combining both conditions gives the optimal output and effort policy:

$$
\begin{aligned}
q_{t} & =\left[1-\theta \sum_{j=0}^{\infty} a_{j} \beta^{j}\right] x_{t} \equiv H x_{t} \\
e_{t} & =\frac{H^{2} B}{2 c(1-\beta A)} \equiv e
\end{aligned}
$$

Outsiders rationally anticipate these policies and can therefore make inferences about the latent variable $x_{t}$ on the basis of their observation of current and past sales $s_{t-j}$ $(j=0,1, \ldots)$. We know that $s_{t}=q_{t}+\epsilon_{t}$. Consequently, observed sales $s_{t}$ are an imperfect (noisy) measure of the output $q_{t}$ chosen by insiders, and therefore also of the latent variable $x_{t}$, as is clear from the following "measurement equation":

$$
s_{t}=H x_{t}+\epsilon_{t} \text { with } \epsilon_{t} \sim N(0, R)
$$

Outsiders know the variance $R$ of the noise and the parameters $A, B$ and $Q$ of the "state equation":

$$
x_{t}=A x_{t-1}+B e+w_{t-1} \text { with } w_{t-1} \sim N(0, Q) \text { for all } t
$$

Using a standard Kalman filter the measurement equation can be combined with the state equation to make inferences about $x_{t}$ on the basis of current and past observations of $s_{t}$. This, in turn, allows outsiders to form an estimate of realized income $\pi_{t}$. It can be shown that the Kalman filter is the optimal filter (in terms of minimizing the mean squared error) for the type of problem we are considering (see Chui and Chen (1991)).

We focus on the "steady state" Kalman filter, which is the estimator $\hat{x}_{t}$ for $x_{t}$ that is obtained after a sufficient number of measurements $s_{t}$ have taken place over time 
for the estimator to reach a steady state. One can show (see Chui and Chen (1991), p78) that the error of the steady state estimator, $x_{t}-\hat{x}_{t}$, is normally distributed with zero mean and variance $P$, i.e., $E_{S, t}\left[x_{t}-\hat{x}_{t}\right]=0$ and $E\left[\left(x_{t}-\hat{x}_{t}\right)^{2}\right]=P$, or $p\left(x_{t} \mid I_{t}\right) \sim N\left(\hat{x}_{t}, P\right)$, where $\hat{x}_{t}$ is given by:

$$
\hat{x}_{t} \equiv E_{S t}\left[x_{t}\right]=A \hat{x}_{t-1}+B e+K\left[s_{t}-H\left(A \hat{x}_{t-1}+B e\right)\right]=\left(A \hat{x}_{t-1}+B e\right) \lambda+K s_{t}
$$

where:

$$
\lambda \equiv(1-K H) \quad \text { and } \quad K \equiv \frac{H P}{H^{2} P+R}
$$

and where $P$ is the positive root of the equation:

$$
P=A^{2}\left[1-\frac{H^{2} P}{H^{2} P+R}\right] P+Q
$$

or equivalently, $P$ is the positive root of the equation:

$$
H^{2} P^{2}+P\left[R\left(1-A^{2}\right)-Q H^{2}\right]-Q R=0
$$

$\mathrm{K}$ is called the "Kalman gain" and it plays a crucial role in the updating process 4

Substituting $\hat{x}_{t-1}$ in (59) by its estimate, one obtains after repeated substitution:

$$
\begin{aligned}
\hat{x}_{t} & =e B \lambda\left[1+\lambda A+\lambda^{2} A^{2}+\lambda^{3} A^{3}+\ldots\right]+K\left[s_{t}+\lambda A s_{t-1}+\lambda^{2} A^{2} s_{t-2}+\lambda^{3} A^{3} s_{t-3}+\ldots\right] \\
& =\frac{e B \lambda}{1-\lambda A}+K \sum_{j=0}^{\infty} \lambda^{j} A^{j} s_{t-j}
\end{aligned}
$$

Using the conjectured solution for $q_{t}$ it follows that outsiders' estimate of income

\footnotetext{
${ }^{42}$ If there is little prior history regarding sales $s_{t}$ then $K_{t}$ itself will vary over time because $P_{t}$, the variance of the estimation error, initially fluctuates over time. Once a sufficient number of observations have occurred $P_{t}$, and therefore $K_{t}$, converge to their stationary level $P$ and $K$. A sufficient condition for the filter to converge is that $\lambda A<1$. The order of convergence is geometric (see Chiu and Chen, 1991, Theorem 6.1 on Page 88).
} 
at time $t$ is given by:

$$
\begin{aligned}
E_{S, t}\left[\pi_{t}\right] & =E_{S t}\left[H x_{t}-\frac{H^{2} x_{t}}{2}-\frac{1}{2} c e^{2}\right] \\
& =\left(H-\frac{H^{2}}{2}\right) \hat{x}_{t}-\frac{1}{2} c e^{2} \\
& =\left(H-\frac{H^{2}}{2}\right)\left[\frac{\lambda B e}{1-\lambda A}+K \sum_{j=0}^{\infty}(\lambda A)^{j} s_{t-j}\right]-\frac{1}{2} c e^{2} \\
& =b+\sum_{j=0}^{\infty} a_{j} s_{t-j}
\end{aligned}
$$

where the last step follows from our original conjecture given by equation (52). This allows us to identify the coefficients $k$ and $a_{j}$ :

$$
\begin{aligned}
b & =\left(H-\frac{H^{2}}{2}\right)\left[\frac{\lambda B e}{1-\lambda A}\right]-\frac{1}{2} c e^{2} \\
a_{j} & =\left(H-\frac{H^{2}}{2}\right) K(\lambda A)^{j}
\end{aligned}
$$

For this to be a rational expectations equilibrium it has to be the case (see equation (55)) that:

$$
\begin{aligned}
H & =1-\theta \sum_{j=0}^{\infty} a_{j} \beta^{j} \\
& =1-\frac{\theta\left(H-\frac{H^{2}}{2}\right) K}{1-\beta \lambda A}
\end{aligned}
$$

Simplifying gives the condition for $H$ in the proposition. Since $a_{j}>0$ for all $j$, one can immediately verify that the second order condition for a maximum is satisfied (see also proof proposition 1).

Finally, we calculate the expected value and variance of the estimate's error: $\pi_{t}-\hat{\pi}_{t}$. We make use of the known result that the error with respect to the steady state estimator for $x_{t}$ is normally distributed with zero mean (i.e., $E_{S, t}\left[x_{t}-\hat{x}_{t}\right]=0$ ) and variance $P$ (i.e., $E_{S, t}\left[\left(x_{t}-\hat{x}_{t}\right)^{2}\right]=P$ ). Hence,

$$
\begin{aligned}
E_{S, t}\left[\pi_{t}-\hat{\pi}_{t}\right] & =E_{S, t}\left[h\left(x_{t}-\hat{x}_{t}\right)\right]=0 \\
E_{S, t}\left[\left(\pi_{t}-\hat{\pi}_{t}\right)^{2}\right] & =E_{S, t}\left[h^{2}\left(x_{t}-\hat{x}_{t}\right)^{2}\right]=h^{2} P
\end{aligned}
$$

where $h \equiv\left(H-\frac{H^{2}}{2}\right)$. 


\section{Proof of Proposition 3}

Actual income is given by:

$$
\pi_{t}=q_{t}-\frac{q_{t}^{2}}{2 x_{t}}-\frac{1}{2} c e^{2}=h x_{t}-\frac{1}{2} c e^{2}
$$

We know from the proof of proposition 2 that $\hat{\pi}_{t}=E_{S, t}\left[\pi_{t}\right]=b+\sum_{j=0}^{\infty} a_{j} s_{t-j}$ (where the values for $b$ and $a_{j}$ are defined there). Lagging this expression by one period, it follows that $\hat{\pi}_{t}-\lambda A \hat{\pi}_{t-1}=h K s_{t}+h \lambda B e-(1-\lambda A) \frac{c e^{2}}{2}$. Substituting this expression into the target adjustment model $(26)$ gives:

$$
\lambda A \hat{\pi}_{t-1}+K h s_{t}+k=\hat{\pi}_{t-1}+(1-\lambda A) \pi_{t}^{*}-\hat{\pi}_{t-1}+\lambda A \hat{\pi}_{t-1}
$$

Simplifying and solving for $\pi_{t}^{*}$ gives equation (28).

\section{Proof of Proposition 4}

Assume that $\hat{x}_{0} \equiv E_{S, 0}\left[x_{0}\right]=x_{0}$ when the equity is issued. As a result, outsiders and insiders predict the same future path for $x_{t}$ at time $t=0$. Indeed,

$$
\begin{aligned}
& E_{S, 0}\left[x_{1}\right]=A \hat{x}_{0}+B e=E_{0}\left[x_{1}\right] \\
& E_{S, 0}\left[x_{2}\right]=A^{2} \hat{x}_{0}+A B e+B e=E_{0}\left[x_{2}\right] \\
& E_{S, 0}\left[x_{3}\right]=\ldots
\end{aligned}
$$

Therefore, insiders and outsiders value the company identically. Let us calculate next the firm value.

$$
\begin{aligned}
E_{0}\left[\pi_{0}\right] & =h x_{0}-\frac{1}{2} c e^{2} \\
\beta E_{0}\left[\pi_{1}\right] & =\beta\left(h A x_{0}+h B e-\frac{1}{2} c e^{2}\right) \\
\beta^{2} E_{0}\left[\pi_{2}\right] & =\beta^{2}\left(h A^{2} x_{0}+h A B e+h B e-\frac{1}{2} c e^{2}\right) \\
\beta^{3} E_{0}\left[\pi_{3}\right] & =\beta^{3}\left(h A^{3} x_{0}+h A^{2} B e+h A B e+h B e-\frac{1}{2} c e^{2}\right) \\
\beta^{4} E_{0}\left[\pi_{4}\right] & =\ldots
\end{aligned}
$$


Hence,

$$
\begin{aligned}
V_{0}= & E_{0}\left[\sum_{j=0}^{\infty} \beta^{j} \pi_{j}\right] \\
= & h x_{0}\left(1+\beta A+\beta^{2} A^{2}+\beta^{3} A^{3}+\ldots\right)+h B e \beta\left(1+\beta A+\beta^{2} A^{2}+\beta^{3} A^{3}+\ldots\right) \\
& +h B e \beta^{2}\left(1+\beta A+\beta^{2} A^{2}+\ldots\right)+\frac{h B e \beta^{3}}{1-\beta A}+\frac{h B e \beta^{4}}{1-\beta A}+\ldots-\frac{c e^{2}}{2(1-\beta)} \\
= & \frac{h}{(1-\beta A)}\left(x_{0}+\frac{B e \beta}{1-\beta}\right)-\frac{1}{2} \frac{c e^{2}}{(1-\beta)} \cdot \diamond
\end{aligned}
$$

\section{References}

Acharya, V., S. C. Myers, and R. G. Rajan (2011): "The Internal Governance of Firms," Journal of Finance, 66, 689-720.

Acharya, V. V., P. DeMarzo, And I. Kremer (2011): "Endogenous Information Flows and the Clustering of Announcements," American Economic Review, forthcoming.

Aminud, Y., J. Y. Kamin, And J. Ronen (1983): "Managerialism and Ownerism in RiskReturn Preferences," Journal of Banking and Finance, 7(2), 189-196.

Bagnoli, M., And S. G. Watts (2010): "Oligopoly, Disclosure and Earnings Management," The Accounting Review, 85(4), 1191-1214.

Beaver, W. H. (1979): "The Nature of Income Measurement," The Accounting Review, 54, $38-46$.

Bolton, P., And A. Faure-Grimaud (2010): "Satisficing Contracts," Review of Economic Studies, 77(3), 937-971.

Burkart, M., D. Gromb, and F. Panunzi (1997): "Large Shareholders, Monitoring, and the Value of the Firm," Quarterly Journal of Economics, 112(3), 693-728.

Demski, J. S., And D. E. M. Sappington (1990): "Fully Revealing Income Measurement," The Accounting Review, 65(2), 363-383. 
Dye, R. A. (1985): "Disclosure of nonproprietary information," Journal of Accounting Research, 23, 123-145.

(1988): "Earnings Management in an Overlapping Generations Model," Journal of Accounting Research, 26, 195-235.

(1990): "Mandatory Versus Voluntary Disclosures: The Cases of Financial and Real Externalities," The Accounting Review, 65(1), 1-24.

Fluck, Z. (1998): "Optimal Financial Contracting: Debt versus Outside Equity," Review of Financial Studies, 11(2), 383-419.

(1999): "The Dynamics of the Management-Shareholder Conflict," Review of Financial Studies, 12, 379-404.

Fudenberg, D., and J. Tirole (1995): "A Theory of Income and Dividend Smoothing Based on Incumbency Rents," Journal of Political Economy, 103(1), 75-93.

Gal-Or, E. (1987): "First Mover Disadvantages with Private Information," Review of Economic Studies, 54(2), 279-292.

GelB, A. (1974): Applied Optimal Estimation. MIT Press, Cambridge (MA).

Goel, A. M., And A. V. Thakor (2003): "Why Do Firms Smooth Earnings?," Journal of Business, 76(1), 151-192.

Graham, J. R. (2003): "Taxes and Corporate Finance: A Review," Review of Financial Studies, 16(4), 1075-1129.

Graham, J. R., C. R. Harvey, and S. Rajgopal (2005): "The economic implications of corporate financial reporting," Journal of Accounting and Economics, 40, 3-73.

HolmströM, B. (1999): "Managerial Incentive Problems: A Dynamic Perspective," The Review of Economic Studies, 66(1), 169-182.

Jin, L., And S. C. Myers (2006): "R2 around the World: New Theory and New Tests," Journal of Financial Economics, 79, 257-292. 
Kamin, J. Y., and J. Ronen (1978): "Smoothing of Income Numbers: Some Empirical Evidence on Systematic Differences Among Management-Controlled and Owner-Controlled Firms," Accounting, Organizations and Society, 3(2), 141-157.

King, R. G., And R. Levine (1993): "Finance and Growth: Schumpeter Might Be Right," Quarterly Journal of Economics, 153, 717-738.

Kyle, A. (1985): "Continuous Auctions and Insider Trading," Econometrica, 53, 1315-1335.

LAmbert, R. A. (1984): "Income Smoothing as Rational Equilibrium Behavior," Accounting Review, 59, 604-618.

Lambrecht, B. M., And S. C. Myers (2007): "A Theory of Takeovers and Disinvestment," Journal of Finance, 62(2), 809-845.

(2008): "Debt and Managerial Rents in a Real-Options Model of the Firm," Journal of Financial Economics, 89(2), 209-231.

(2011): “A Lintner Model of Payout and Managerial Rents," Journal of Finance, forthcoming.

Lieber, Z., E. Melnick, And J. Ronen (1983): "The Filtering of Transitory Noise in Earnings Numbers," Journal of Forecasting, 2, 331-350.

LintneR, J. (1956): "Distribution of Incomes of Corporations among Dividends, Retained Earnings, and Taxes," American Economic Review, 46, 97-113.

Milgrom, P. R., And J. Roberts (1982): "Limit Pricing and Entry Under Incomplete Information: An Equilibrium Analysis," Econometrica, 50, 443-460.

Moore, J. C., L. L. Stinson, and E. J. Welniak (2000): "Income Measurement Error in Surveys: A Review," Journal of Official Statistics, 16(4), 331-361.

Myers, S. C. (2000): "Outside Equity,” Journal of Finance, 55(3), 1005-1037.

Myers, S. C., AND N. S. MAJluf (1984): "Corporate Financing and Investment Decisions when Firms have Information that Investors do not have," Journal of Financial Economics, $13,187-221$. 
Prencipe, A., S. Bar-Yosef, P. Mazzola, and L. Pozza (2011): "Income Smoothing in Family-controlled Companies: Evidence from Italy," Corporate Governance: An International Review, 19(6), 529-546.

Rajan, R. G., And L. Zingales (1998): "Financial Dependence and Growth," American Economic Review, 88, 559-586.

Riordan, M. (1985): "Imperfect Information and Dynamic Conjectural Variation," The Rand Journal of Economics, 16, 41-50.

Roberts, M. R., and R. Michaely (2007): "Corporate Dividend Policies: Lessons from Private Firms," Ssrn working paper 927802.

Ronen, J., And S. SAdan (1981): Smoothing Income Numbers: Objectives, Means, and Implications. Addison-Wesley Publishing Company, Reading, Mass.

ROYCHOWDHURY, S. (2006): "Earnings management through real activities manipulation," Journal of Accounting and Economics, 42(3), 335-370.

Simon, H. A. (1955): "A Behavioral Model of Rational Choice," Quarterly Journal of Economics, 69(1), 99-118.

- (1987): "Satisficing," in The New Palgrave: A Dictionary of Economics, ed. by J. Eatwell, M. Milgate, and P. Newman, pp. 243-245. Stockton Press, New York.

Stein, J. (1989): "Efficient Capital Markets, Inefficient Firms: A Model of Myopic Corporate Behavior," Quarterly Journal of Economics, 104(4), 655-669.

Trueman, B., And S. Titman (1988): "An Explanation for Accounting Income Smoothing," Journal of Accounting Research, 26, 127-139.

Tucker, J. W., And P. A. Zarowin (2006): "Does Income Smoothing Improve Earnings Informativeness?," The Accounting Review, 81(1), 251-270. 


\section{Figure 1: Production efficiency}

The figure examines how production efficiency is affected by the variance of measurement errors $(R)$, the variance of the latent cost variable $x_{t}(Q)$, the autocorrelation at lag one of the latent cost variable $(A)$ and outsiders' real ownership stake $(\theta)$. Production efficiency is measured by comparing actual effort $\left(e_{t}\right)$, unconditional mean output $\left(E\left(q_{t}\right)\right)$ and unconditional mean income $\left(E\left(\pi_{t}\right)\right)$ relative to their first-best level. The baseline parameter values used to generate the figures in this paper are: $A=0.8, B=1, c=1, Q=4, R=1, \beta=0.95$ and $\theta=0.8$.

A) Production efficiency as a function of $R$

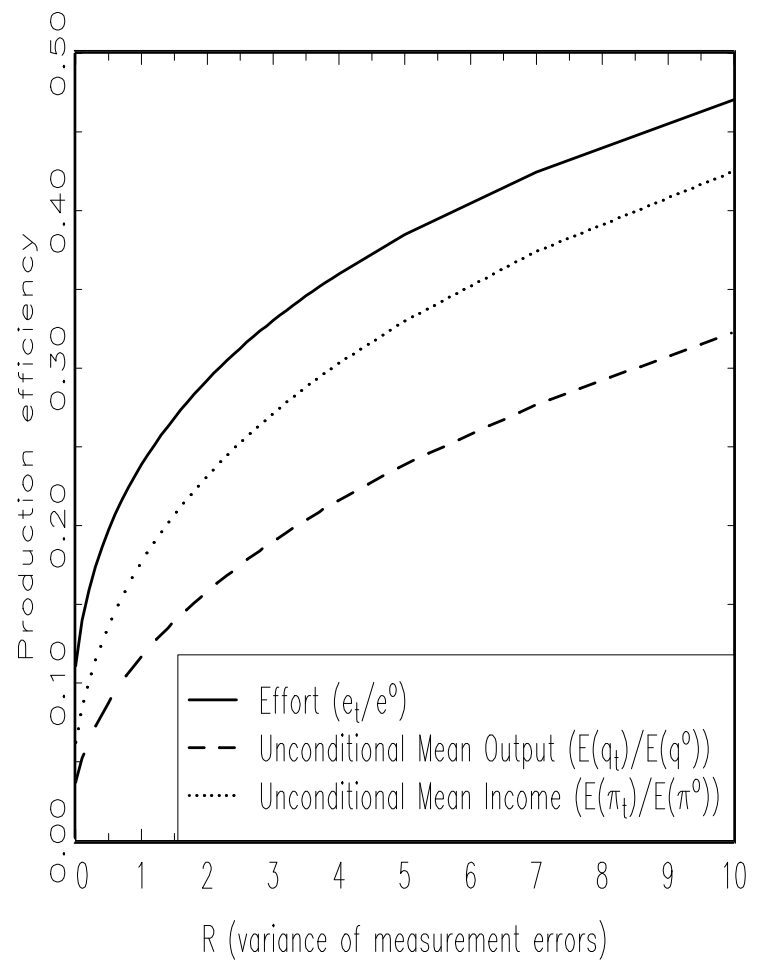

c) Production efficiency as a function of A

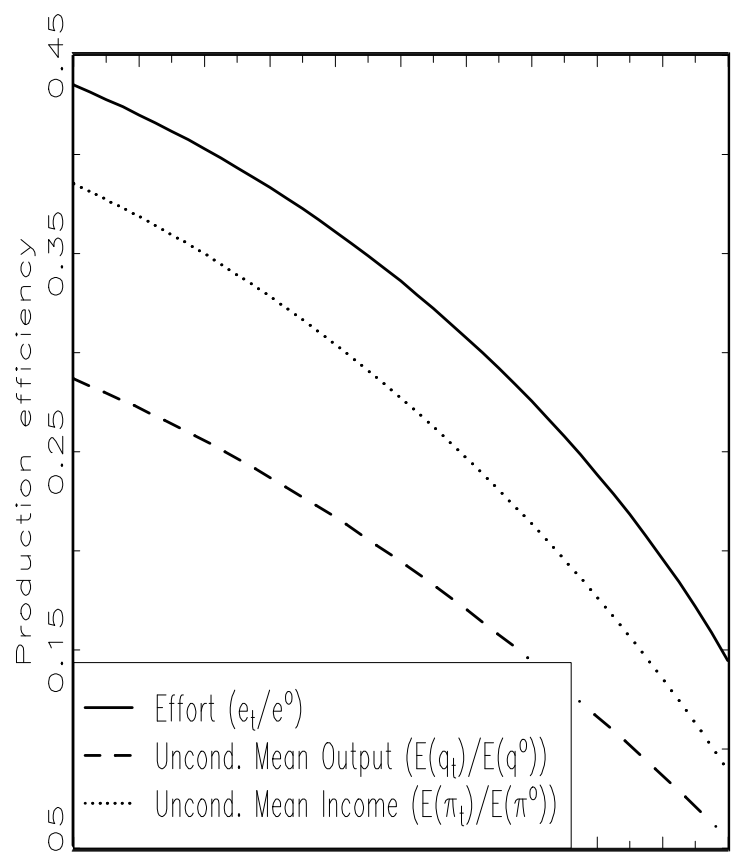

B) Production efficiency as a function of $Q$

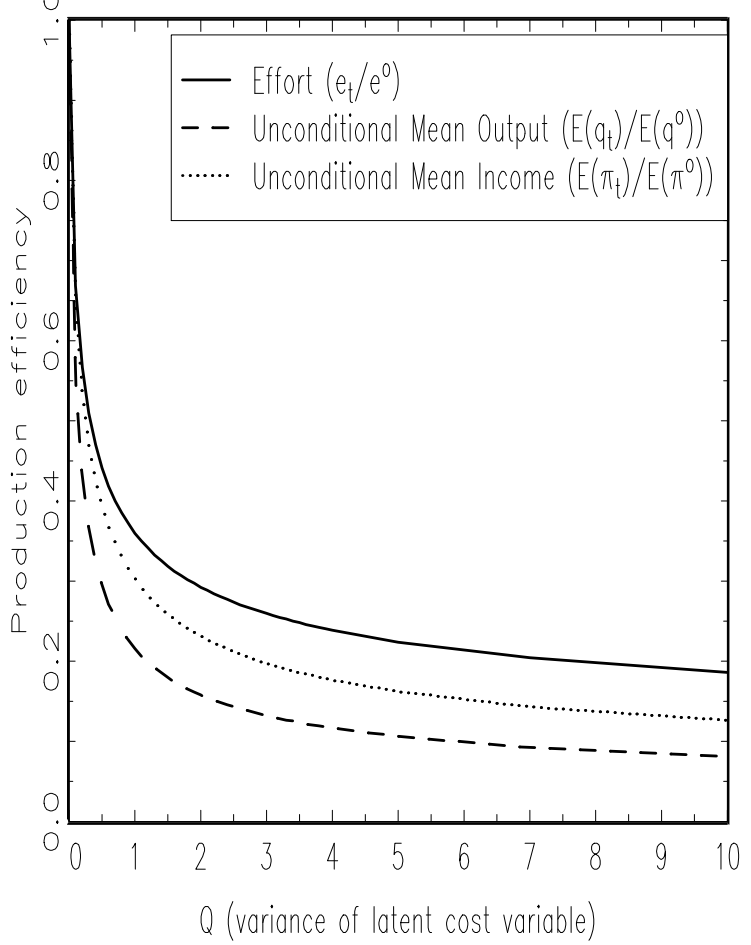

D) Production efficiency as a tunction of $v$

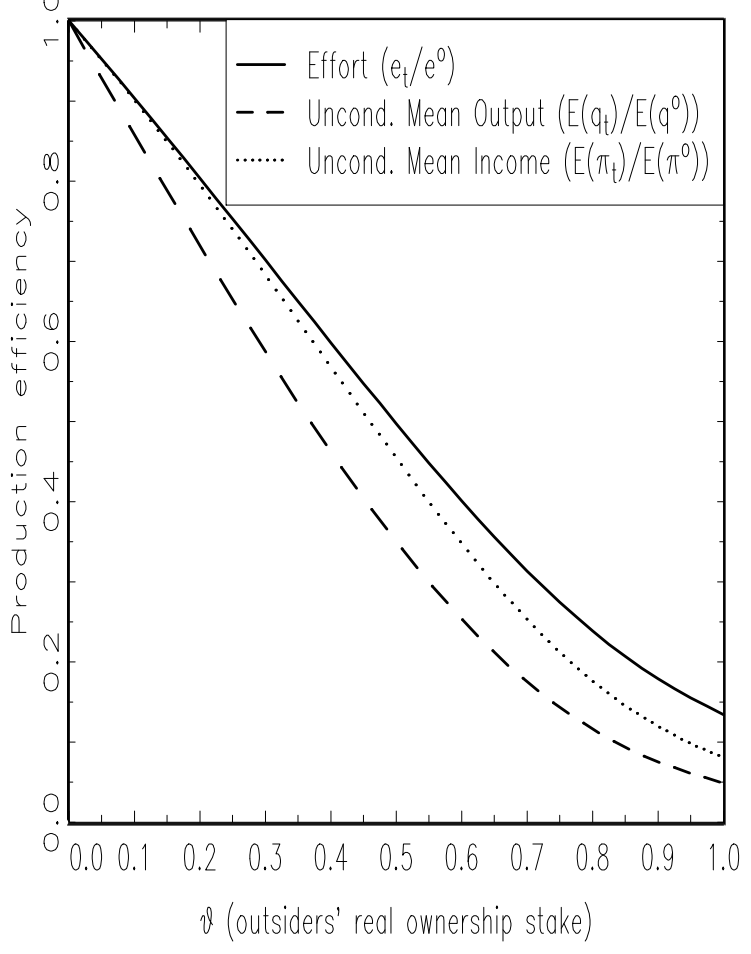




\section{Figure 2: Speed of Adjustment}

The figure examines how outsiders' real ownership stake $(\theta)$, the autocorrelation at lag one of the latent cost variable $(A)$, the variance of measurement errors $(R)$ and the variance of the latent cost variable $x_{t}(Q)$ affect the speed of adjustment (SOA) of reported income to the income target. The speed of adjustment is given by $S O A=1-\lambda A$. The total amount of smoothing (measured by $A \lambda$ ) is split up in its two components: financial smoothing (measured by $A \lambda[H=1]$ ) and real smoothing (measured by $A \lambda-A \lambda[H=1]$ ). The baseline parameter values used to generate the figure are the same as before, i.e., $A=0.8, B=1, c=1, Q=4, R=1, \beta=0.95$ and $\theta=0.8$.

A) SOA as a function of v

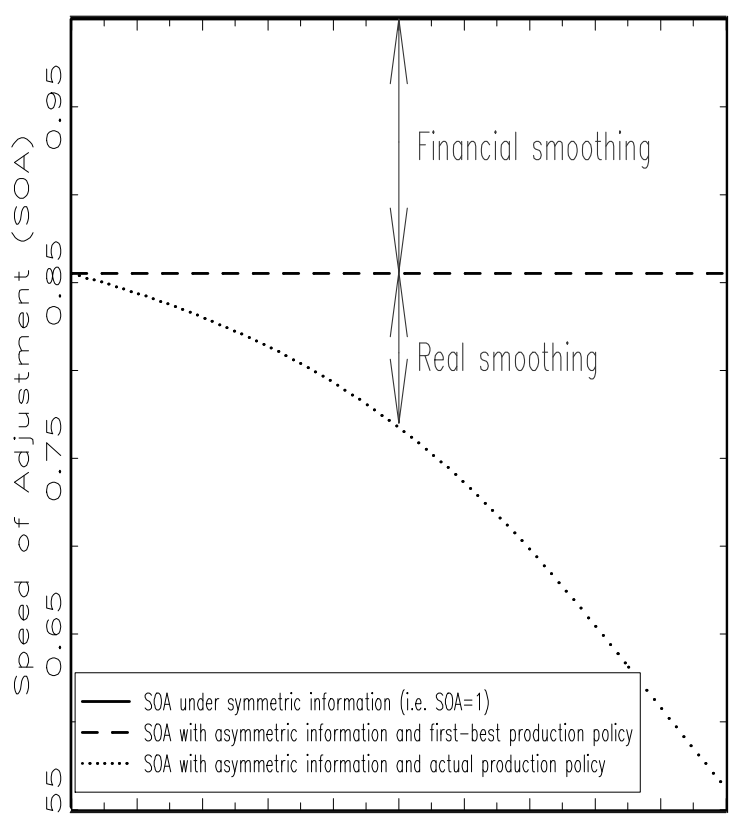

loutsiders' real ownership stake

c) $S 0 A$ as a function of $R$

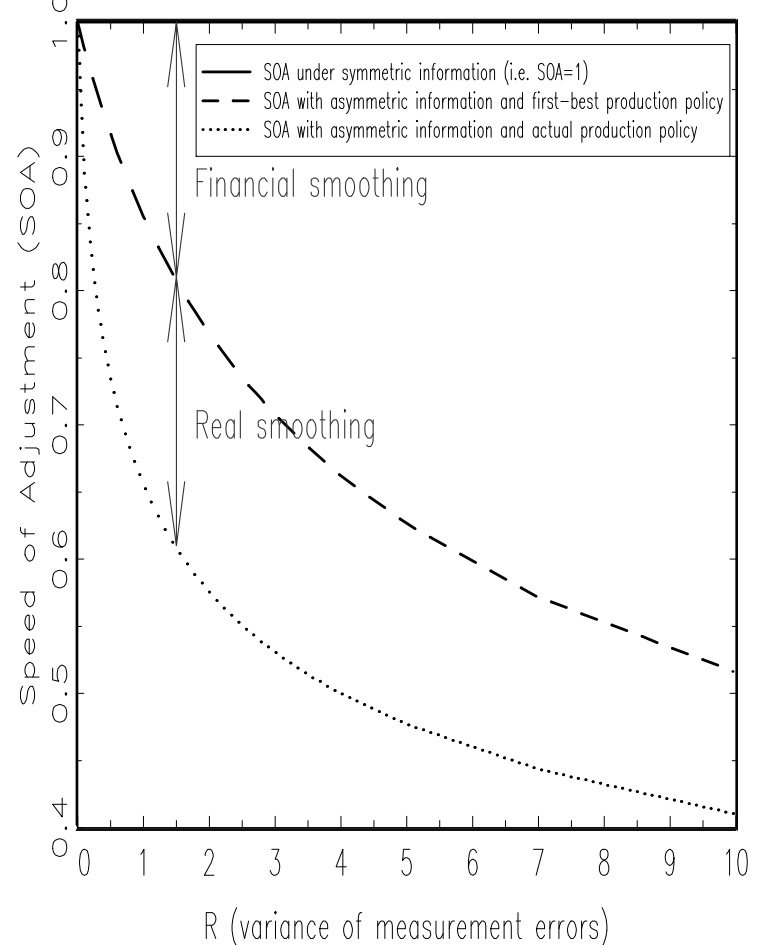

B) SOA as a function of A

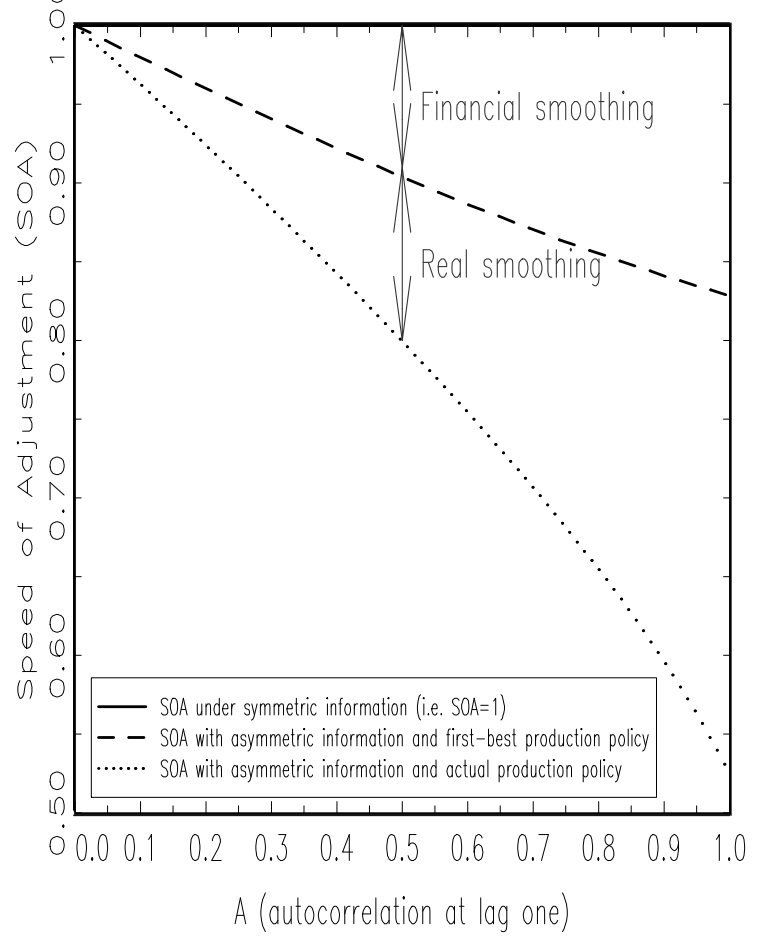

D) SOA as a function of 0

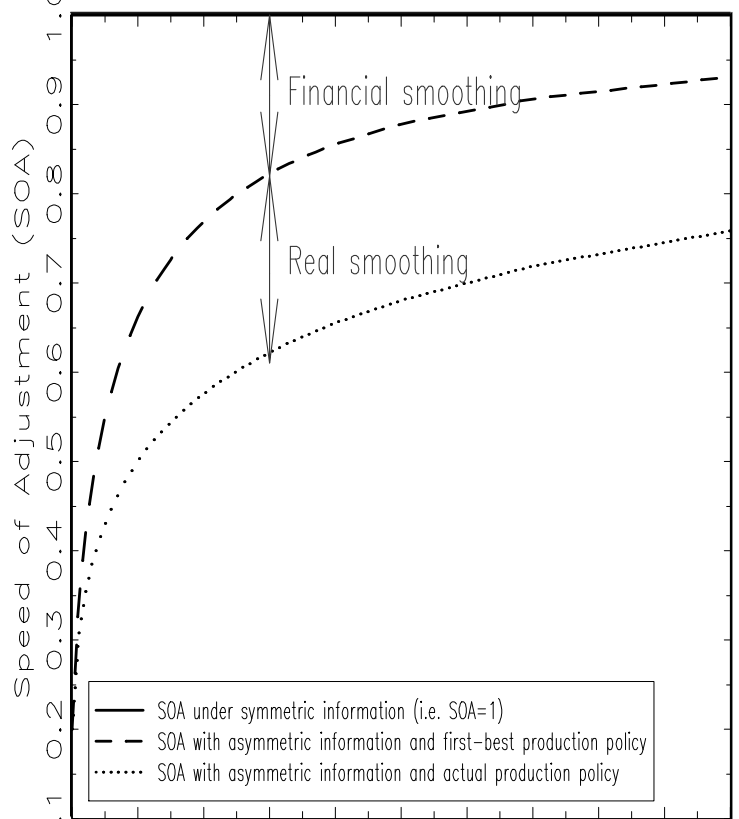


Figure 3: Total firm value and outside equity value

The figure plots the total initial firm value $V_{0}$ (panel A) and outside equity value $S_{0}$ (panel B) as a function of outsiders' real ownership stake $(\theta)$ for three different levels of audited disclosure quality $(\kappa)$. The inverted U-shaped curves in panel B are the so-called "outside equity Laffer curves". The baseline parameter values used to generate the figure are the same as before, i.e., $A=0.8, B=1, c=1, Q=4, R=1, \beta=0.95$ and $\theta=0.8$.

\section{A) Total Firm Value as a function of $\theta$ and $k$}

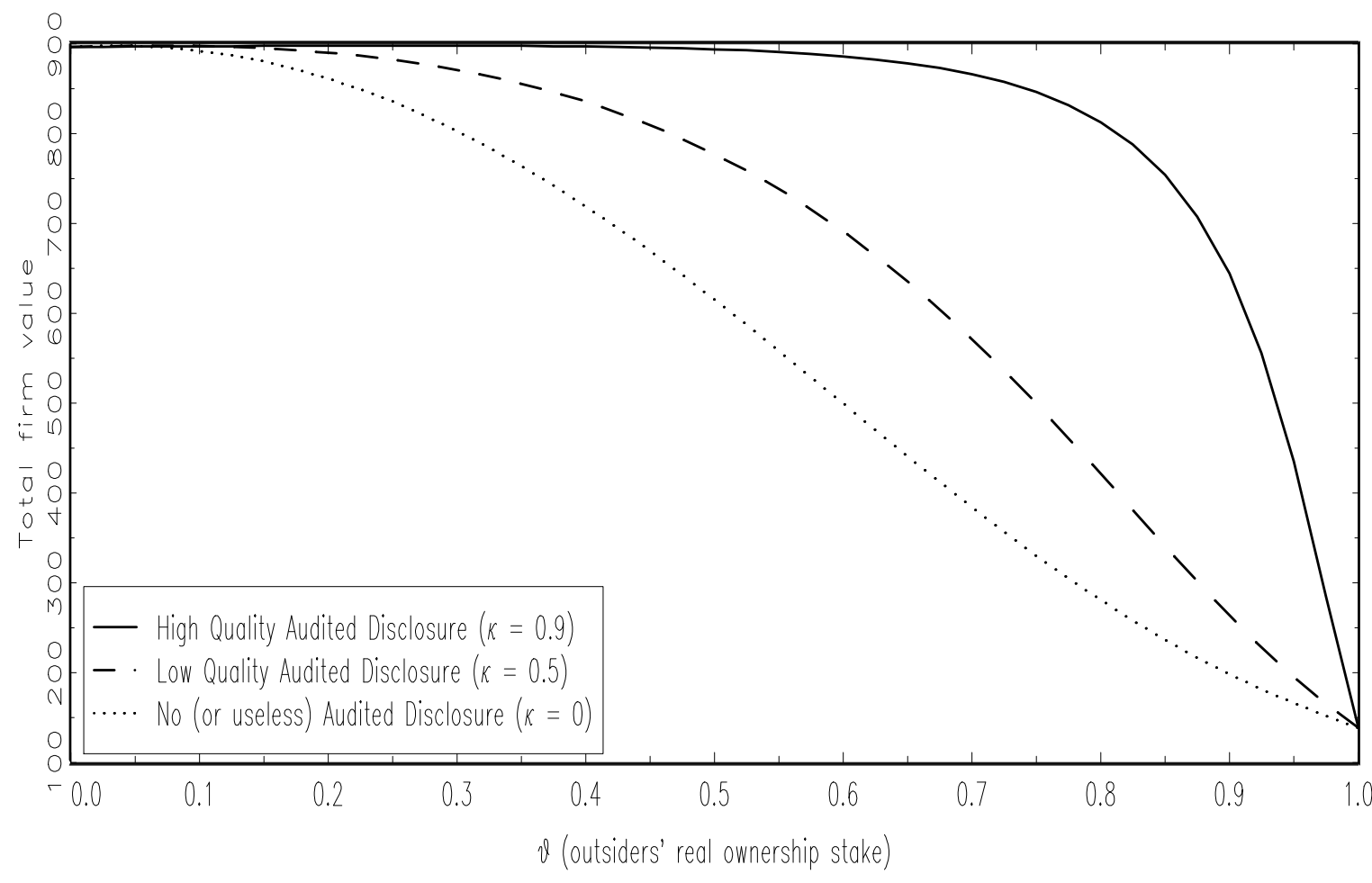

B) Outside Equity Value as a function of $v$ and $k$

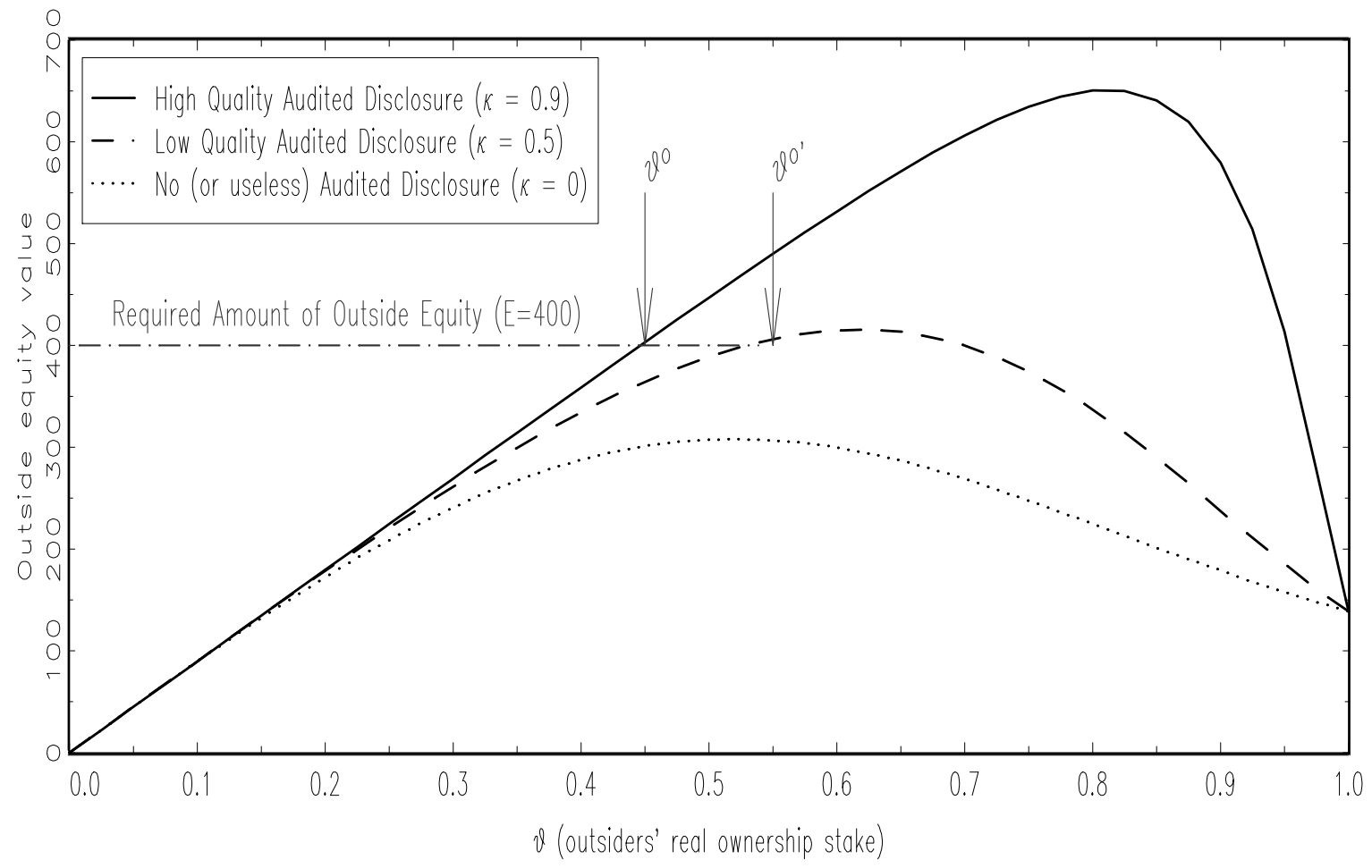

